\title{
European guidelines on managing adverse effects of medication for ADHD
}

\author{
J. Graham - T. Banaschewski $\cdot$ J. Buitelaar $\cdot$ D. Coghill $\cdot$ M. Danckaerts $\cdot$ R. W. Dittmann $\cdot$ \\ M. Döpfner · R. Hamilton - C. Hollis - M. Holtmann - M. Hulpke-Wette $\cdot$ M. Lecendreux \\ E. Rosenthal · A. Rothenberger · P. Santosh · J. Sergeant $\cdot$ E. Simonoff $\cdot$ E. Sonuga-Barke \\ I. C. K. Wong - A. Zuddas - H.-C. Steinhausen - E. Taylor • (for the European Guidelines Group)
}

Received: 24 March 2010/Accepted: 6 October 2010/Published online: 3 November 2010

(C) The Author(s) 2010. This article is published with open access at Springerlink.com

\begin{abstract}
The safety of ADHD medications is not fully known. Concerns have arisen about both a lack of contemporary-standard information about medications first licensed several decades ago, and signals of possible harm arising from more recently developed medications. These relate to both relatively minor adverse effects and extremely serious issues such as sudden cardiac death and
\end{abstract}

Meeting costs of the Guidelines was supported by: Lilly, Medice, Novartis, UCB, Shire. No fees were paid to participants.

\section{J. Graham ( $\square)$}

Child and Adolescent Psychiatry,

The Centre for Child Health, Dundee, UK

e-mail: JGraham3@nhs.net

T. Banaschewski $\cdot$ M. Holtmann

Department of Child and Adolescent Psychiatry and

Psychotherapy, Central Institute of Mental Health,

J 5, Mannheim, Germany

T. Banaschewski · A. Rothenberger

Department of Child and Adolescent Psychiatry,

University of Göttingen, Göttingen, Germany

J. Buitelaar

Karakter Child and Adolescent Psychiatry University Center

Nijmegen, Nijmegen, The Netherlands

D. Coghill

Centre for Neuroscience, University of Dundee,

Dundee, Scotland, UK

\section{Danckaerts}

Department Child and Adolescent Psychiatry,

UZ Gasthuisberg, Leuven, Belgium

R. W. Dittmann

Psychosomatic Department, Children's Hospital,

University of Hamburg, Hamburg, Germany suicidality. A guidelines group of the European Network for Hyperkinetic Disorders (EUNETHYDIS) has therefore reviewed the literature, recruited renowned clinical subspecialists and consulted as a group to examine these concerns. Some of the effects examined appeared to be minimal in impact or difficult to distinguish from risk to untreated populations. However, several areas require further study to allow a more precise understanding of these risks.

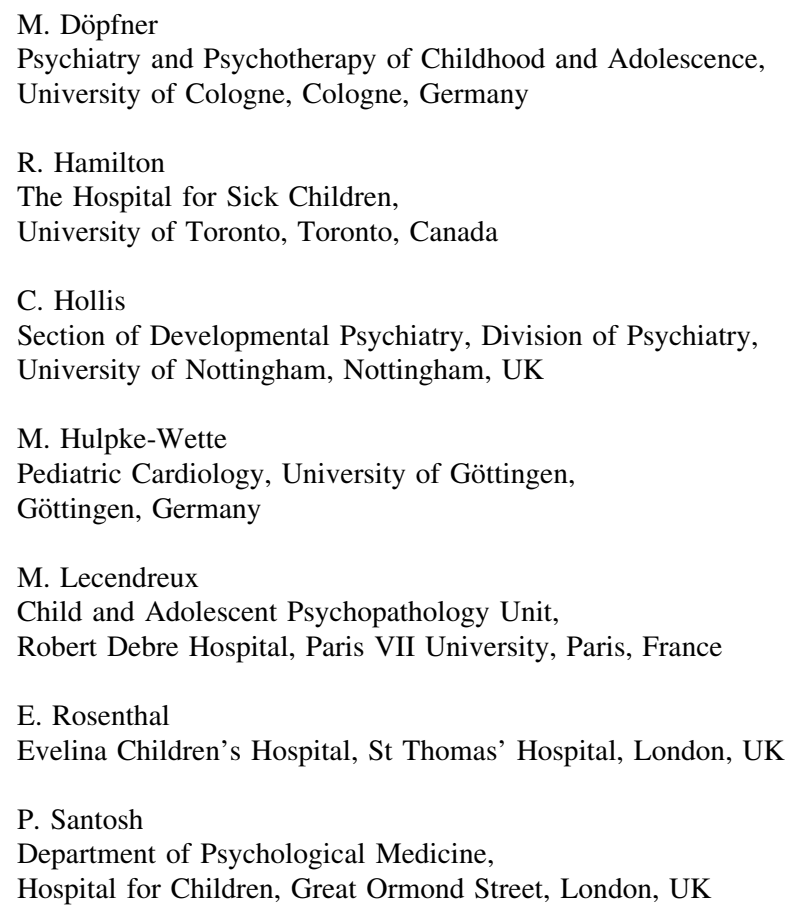

M. Lecendreux

Child and Adolescent Psychopathology Unit,

Robert Debre Hospital, Paris VII University, Paris, France

E. Rosenthal

Evelina Children's Hospital, St Thomas' Hospital, London, UK

P. Santosh

Department of Psychological Medicine,

Hospital for Children, Great Ormond Street, London, UK 
Keywords ADHD - HKS - Medication - Adverse · Guidelines · European · Children

\section{Introduction}

Attention-deficit hyperactivity disorder (ADHD) is one of the most common mental disorders with a worldwide mean prevalence of around 5\% in children [109] and 3\% among adults [40]. The disorder persists into adulthood in a significant proportion of the affected individuals and, most commonly, its course is complicated due to frequent comorbidities and impaired psychosocial functioning. Thus, ADHD requires continuing professional care on the level of both assessment and intervention. Guidelines help clinicians to provide high-quality care to their patients by delivering evidence-based state of the art management strategies. This European guidelines group has contributed to the process through previous publications [13, 140].

It is widely accepted that intervention in ADHD should be based on multimodal treatment. Amongst its various components, drug treatment is of specific value and relevance to the patients. Accordingly, methylphenidate, dexamfetamine and atomoxetine in particular are widely used in European countries and North America for the treatment of ADHD. They are effective drugs, and meta-analyses

\section{J. Sergeant}

Department of Clinical Neuropsychology,

Faculty of Psychology and Education, Vrije Universiteit,

Amsterdam, The Netherlands

E. Simonoff

Social, Developmental and Psychiatry Research Centre,

Institute of Psychiatry, London, UK

E. Sonuga-Barke

School of Psychology, University of Southampton,

Southampton, UK

E. Sonuga-Barke

Department of Experimental Clinical and Health Psychology,

Ghent University, Ghent, Belgium

\section{C. K. Wong}

University of London and Institute of Child Health,

University College London, London, UK

\author{
A. Zuddas \\ Child Neuropsychiatry, Department of Neuroscience, \\ University of Cagliari, Cagliari, Italy \\ H.-C. Steinhausen \\ Department of Child and Adolescent Psychiatry, \\ University of Zürich, Zürich, Switzerland \\ E. Taylor \\ MRC Social Genetic Developmental and Psychiatry Centre, \\ Institute of Psychiatry, London, UK
}

investigating their use have led to our guidelines recommending their use as part of a comprehensive treatment programme [13, 140].

There are hundreds of trials involving the ADHD drugs, all of them indicating that they are associated with a range of adverse effects that are generally acceptable, because they are mild and/ or temporary. These have been summarised in other reviews: for example, Graham and Coghill [49] describe several domains being involved. These symptoms predominantly include neurological effects (headache, dizziness, insomnia, seizures); psychiatric effects (mood/anxiety, tics, psychotic symptoms); and gastroenterological effects including poor appetite and overlapping with possible growth restriction. Whilst the majority of evidence addresses a similar age group and developmental span (middle childhood and adolescence) there are also data to inform relative risks of prescription of stimulants and atomoxetine in younger age groups $[6,74]$ — which suggest greater sensitivity to emotionality following prescription of either drug — as well as suggestions that older/adult groups and cognitively impaired individuals may also display differential risks (although these are not well evidenced).

Despite existing literature, there are residual concerns that the true safety of these drugs is not fully known. For the most commonly used drug, methylphenidate, introduction and licensing of the original immediate release form came in the 1960s, and hence before modern standards of clinical trials and post-licensing surveillance were established. Also the introduction and regulatory approval of newer forms of the drugs, which have been accompanied by enhanced standards of monitoring, have resulted in signals of potential harm, raising the possibility that some of these adverse outcomes may also apply to methylphenidate. For example, of all spontaneous reports of adverse drug reactions in Denmark between 1998 and 2007, drug reactions were classed as 'serious' when reported in 52 and 18 children taking methylphenidate and atomoxetine, respectively [5]. Public and professional concern has been raised about the potential for severe reactions, even including death, and for the generation of misuse. These uncertainties make it possible either that vulnerable children are being exposed to unreasonable hazard, if real risks go undetected, or that children are being denied the benefit of medication if perceived risks are exaggerated.

We have therefore reviewed the published literature on adverse effects of the drugs that are licensed in Europe, and most commonly used, for the treatment of ADHD or hyperkinetic disorder. As such we have specifically examined: immediate release methylphenidate, modified release methylphenidate, dexamfetamine and mixed amfetamine compounds, and atomoxetine. Several drugs are not licensed in Europe and are either unavailable (e.g. guanfacine), or uncommonly used (e.g. modafinil, clonidine and tricyclic antidepressants). These unlicensed drugs were not included 
in the review, but are referred to where relevant to understanding of the recommended medications. We have focussed on safety in children and adolescents, but the review has been additionally informed by adult data. Meta-analysis was not feasible because of heterogeneity in information reported; where quantitative data are available we have used the indices reported in the papers. In addition to addressing the published literature we requested information from the licence holders about unpublished safety information. The Eunethydis ADHD Guidelines Group (EAGG) meeting was in part supported by the pharmaceutical industry and Longterm Effect of Psychotropic Medication in Children Clinical Research Group of UK Mental Health Research Network (including some travel and hotel costs). In preparing for the meeting, companies were requested to supply: data sent to the European Medicines Agency (EMA), all published papers, posters and submitted manuscripts concerning safety issues with their product(s) related to ADHD treatment. Data submitted to the EMA were not given to the group, but the remaining items were provided. In addition, all companies were invited to make a presentation at the EAGG meeting and/or answer specific questions from the group. The manuscript submitted for publication was sent to all companies for comment with the decision to revise being held by EAGG. We also consulted specialists in paediatrics, cardiology and endocrinology; and held a series of consensus conferences, examining incidence, causality and potential impact of risks, through which we have formulated advice to clinicians about the frequency and severity of each and the means of reducing harm or reacting to adverse events if they should occur. The evidence and advice will be divided into the main different areas of concern.

\section{Cardiac adverse events}

The cardiac safety of drugs used to treat ADHD remains of concern to many prescribers and families, following reports of sudden cardiac deaths of individuals taking drugs for ADHD. Stimulants are also well known to exert both pressor and chronotropic cardiac effects. Child and adolescent psychiatrists and paediatricians who are aware of black box advisory labels and advice to monitor cardiac parameters may remain uncertain as to the true risks in both cardionormal children and those with existing risk factors.

\section{Frequency of cardiac adverse events in treated and untreated populations}

Sudden death in children and adolescents

In contrast to adults, sudden death occurs only rarely in the general paediatric population. Sudden death rates range from 0.8 to $8.5 / 100,000$ patient-years [20, 30, 98, 99, 159]. The median of these published sudden death rates in children is at $1.2-1.3 / 100,000 /$ year. Sudden death in children and adolescents is associated with both known and previously unrecognized cardiac conditions. Among young persons with known congenital heart disease, the highest risks of sudden death $(0.2 \%$ per year) occur with specific conditions such as aortic stenosis [128].

In children with ADHD, the risk of death from all causes is estimated at 58.4/100,000 patient-years [157], whereas the risk of sudden unexplained death is unknown. The Food and Drugs Administration (FDA) in the USA, and Health Canada identified 25 sudden deaths in individuals prescribed ADHD medications from post-marketing data between 1999 and 2003, raising concerns of a possible association. 12 of these individuals were in the 1-18 years bracket. However, when the number of patient-years of prescribed medication was incorporated into the evaluation, the frequency of reported sudden death per year of ADHD therapy with methylphenidate, atomoxetine or amfetamines among children was $0.2-0.5 / 100,000$ patientyears [99]. The analysis of 10 -year adverse-event reporting in Denmark resulted in no sudden deaths in children taking ADHD medications [5]. While it is recognised that adverse events are frequently under-reported in general, it is likely that sudden deaths in young individuals on relatively new medications may be better reported. Death rates per year of therapy, calculated using the adverse events reporting system (AERS) reports and prescription data, are equivalent for two ADHD drugs (dexamfetamine and methylphenidate): 0.6/100,000/year [37]. (The accuracy of these estimates is limited however, for instance because in moving from number of prescriptions to patient-year figures assumptions must be made about the length of each prescription). It seems likely, using these best available data, and assuming a 50\% under-reporting rate, that the sudden death risk of children on ADHD medications is similar to that of children in general. Caveats to the above include the observation that 2 of the 25 sudden deaths on ADHD medication occurred with initiation of stimulant medication. Thus, as with most therapies, an exceedingly rare but real risk of sudden death cannot be completely excluded. If childhood deaths on ADHD medications are under-reported to a greater degree than we have assumed, then some incremental risk could potentially be present.

A recently published study compared stimulant use in two matched groups of 564 young people aged 7-19 years: one group who had suffered sudden unexplained death, and the other who had died as passengers in motor vehicle accidents [48]. Stimulant use was found in $10(1.8 \%)$ of the former group versus $2(0.4 \%)$ of the latter group. The odds ratio was reported to be 7.4 (95\% CI 1.4-74.9); from which 
the authors conclude a possible association of stimulant use with sudden death. The FDA, however, has suggested caution in interpreting these findings, citing possible methodological flaws. In addition, the physical and mental health comorbidities associated with the disorder that requires stimulant treatments may themselves increase the risk of sudden death from other causes.

In another study the incidence of sudden death in children prescribed ADHD drugs was not found to be statistically different to that in the general population; but this study was limited by its sample size [91]. As sudden death in children is so rare, very large epidemiological studies are required to adequately examine this question. At the time of writing, some studies of ADHD medication risk remain pending, and practice should be reassessed in the event of any new convincing data. For example, the FDA is currently conducting a large epidemiological study $(500,000$ patients) to further examine this question.

\section{Hypertension}

The definition of hypertension in children (blood pressure beyond the 95th centile for age and height) suggests that about $5 \%$ of children would technically be hypertensive to a level requiring investigation and possible treatment (including pharmacotherapy) prior to administration of stimulant drugs. In theory, every childhood population should have this number of children receiving measures to reduce their blood pressures below the 95th centile (and below the 90th centile if there is evidence of end organ damage) [4]. In practice, however, routine screening for and treatment of hypertension in children has not been widely implemented as a public health standard of care. The actual values for blood pressure at the various percentiles differ slightly in European countries [62, 75, 88], so local norms should be used wherever possible. The average blood pressure in children is increasing; perhaps in part due to increased prevalence of obesity [97].

All stimulant medications and atomoxetine are reported to cause elevations in blood pressure [150]. While the average increases range from $1-4 \mathrm{mmHg}$ systolic and 1-2 mmHg diastolic, this small average change includes patients where the rise in blood pressure is more significant, and there are also data showing increases above the 95th centile in individuals taking ADHD medications. For categorically measured hypertension, controlled trial data are available for atomoxetine and indicate that elevations above the 95th percentile are seen in $6.8 \%$ of patients (systolic) and $2.8 \%$ (diastolic), in comparison to 3 and $0.5 \%$, respectively, of patients treated with placebo [150]. Categorical hypertension data for methylphenidate are not published so far but are likely to be of a similar order of magnitude on the basis of the changes in mean pressures.
The patient information leaflet for methylphenidate products in Europe indicates that the drug may increase systolic and diastolic blood pressure by more than $10 \mathrm{mmHg} .{ }^{1}$

Heart rate increases

Stimulant and non-stimulant medications are recognised to cause a small increase in heart rate averaging 1-2 beats per minute [146, 150]. The averaging of data in clinical studies can hide a small proportion where the increment is larger; indeed up to 50 beats/min in rare cases [150].

\section{QT interval prolongation}

Prolongation of the QTc interval in individuals (without a congenital long QT syndrome or previously recognised long QT interval) can be caused by a variety of medications and is a recognised risk factor for ventricular tachyarrhythmias and sudden death [160]. Thus, the potential effects of ADHD medications on the QT interval are important given the concerns raised about the safety of this group of medications. The average QTc interval is not changed significantly by any of the drug groups (methylphenidate, mixed amfetamine salts and atomoxetine). However, as with raised blood pressure, the average changes in any study cohort may not identify significant increases in a subgroup of individuals which are averaged out by decreases in another subgroup. More important than the average change in a study cohort is the proportion with an increment in QTc to above the safe threshold (usually accepted as being above 470-500 ms). Such data for the various preparations are available to regulatory organizations but are not yet in the public domain. Unless new data emerge for a particular subgroup, there is currently no indication to monitor for QTc changes when stimulants are prescribed. Finally, it should be noted that measurement of the QTc interval is not without difficulties, and at least six alternative methods of rate correction are available [83, 149].

QTc prolongation (and sudden death and increased heart rate) have been reported with methylphenidate and dexamfetamine [99] and atomoxetine [34]. The assessment of sudden deaths with relation to patient-years of treatment described atomoxetine deaths at 0.5 per 100,000 patientyears, and methylphenidate at 0.2 per 100,000 patient-years [5]. Overall, however, insufficient data exist to truly demonstrate any differential sudden death risk for different drugs. A recent retrospective study concluded that exposure to methylphenidate and amfetamine salts showed similar risks for cardiac emergency department visits [158].

\footnotetext{
$\overline{1}$ http://www.ema.europa.eu/htms/human/referral/article31/methylphenidate.htm.
} 
Relative impact of cardiac risk, and mediating factors

Sudden death, whether occurring in children or adults, is of course a disastrous event. That individuals with an undetected cardiac pathology, such as a cardiomyopathy or conduction problem, might as a result of ADHD medication, have their illness at best 'revealed' or at worst aggravated with a potentially fatal outcome, remains to be excluded as an extremely rare possible outcome.

Despite the lack of a public health approach to hypertension in younger people, it is recognised that intimal plaque formation may occur as a result of hypertension in children [19], and in the long-term even small increases of blood pressure are associated with an increased incidence of cerebrovascular disease in adults [81]. Other consequences include end organ damage such as: left ventricular hypertrophy, retinopathy, and nephropathy with proteinuria. In adults a $2 \mathrm{mmHg}$ lowering of usual systolic blood pressure would result in about $10 \%$ lower stroke mortality and about $7 \%$ lower mortality from ischemic heart disease or other vascular causes in middle age [81].

In terms of potential mechanisms whereby ADHD medications may cause cardiac risk, any persistent heart rate increases seen with ADHD treatment are usually very small and unlikely to be a risk factor for exacerbation of underlying cardiac pathology, but a less common larger persistent rise in heart rate may theoretically do so. Similarly, significant QTc prolongation (to intervals above $470-500 \mathrm{~ms}$ ) is known to result in a risk of potentially fatal arrhythmias, such as Torsade de Pointes [100].

A personal history of cardiac symptoms (e.g. syncope on exercise) and a positive family history of sudden death below the age of 40 years, or of death associated with exercise are particular risks for sudden death. This risk might potentially be increased by treatment by drugs with pressor adverse effects, although evidence is lacking, and sudden death more commonly will be the first presentation of the underlying condition. Other risks include pre-existing arrhythmias and channelopathies (e.g. long QT syndrome).

With respect to hypertension, an elevated blood pressure before ADHD treatment or appearing in the course of treatment, a positive family history and other risk factors for cardiac disease are likely to mediate risk. Another mediator may be obesity; children with a BMI above the 95th percentile had a hypertension prevalence of $10.7 \%$ in one study; in contrast to children with a BMI below 85th percentile, who had a hypertension prevalence of only $2.6 \%$ [130].

It is not known whether children with ADHD have a coexisting increased incidence of hypertension, although there is evidence of a link [66]. The confounder is of course stimulant therapy in this population.
In the FDA post-marketing reports, many of the identified subjects were receiving polypharmacy, which therefore may moderate risk of sudden death. Finally, cytochrome P450 (CYP 2D6) metaboliser status has been shown to be a modifying factor in the adverse effects of atomoxetine [93].

\section{Management of cardiac risk}

For ADHD patients without known heart disease-the ADHD specialist, whether psychiatrist or paediatrician-is the appropriate person for evaluation of benefit and risk, and the making of recommendations for medication therapy.

Congenital heart disease patients have a slightly higher incidence of ADHD [127], and those affected might well benefit from ADHD therapies; including appropriately prescribed medication. During such treatment, input from a paediatric cardiologist/electrophysiologist may be useful, although the ADHD specialist remains the appropriate individual to evaluate the benefit and risk and make recommendations for medication therapy in this case. In a setting where there may truly be a risk of sudden death (e.g. the congenital long QT syndrome), a frank discussion of these aspects between the family, ADHD specialist and paediatric cardiologist or electrophysiologist should help to refine the acceptability for the individual patient.

Pre-treatment checking and monitoring of pulse and blood pressure are recommended with any ADHD medication in all patients with ADHD, with frequency of monitoring thereafter usually arbitrarily recommended as either three [67] or six monthly [140], but clearly this requirement may vary in individual cases. Sustained elevated blood pressure before or on treatment with stimulants requires assessment and treatment. Blood pressure should be measured prior to treatment and at each visit and converted to a centile score using the appropriate chart. If the first recording is elevated then it should be repeated at least twice and if still elevated, and above the 95th centile, then referral to a paediatric hypertension specialist is required, for 24-h ambulatory blood pressure recordings to confirm the diagnosis and to initiate any investigations for end organ damage. In patients already treated for ADHD, alternatively, a dose reduction or drug holiday could be proposed before referring to the specialist, the latter principally to confirm the potential role of the drug in the hypertensive state. Further management will depend on the severity of the blood pressure elevation and in consultation with the ADHD specialist might include antihypertensive treatment in addition to the stimulants, or discontinuation of the medication. A flow chart for both the ADHD specialist and hypertension specialist is attached (Fig. 1). 


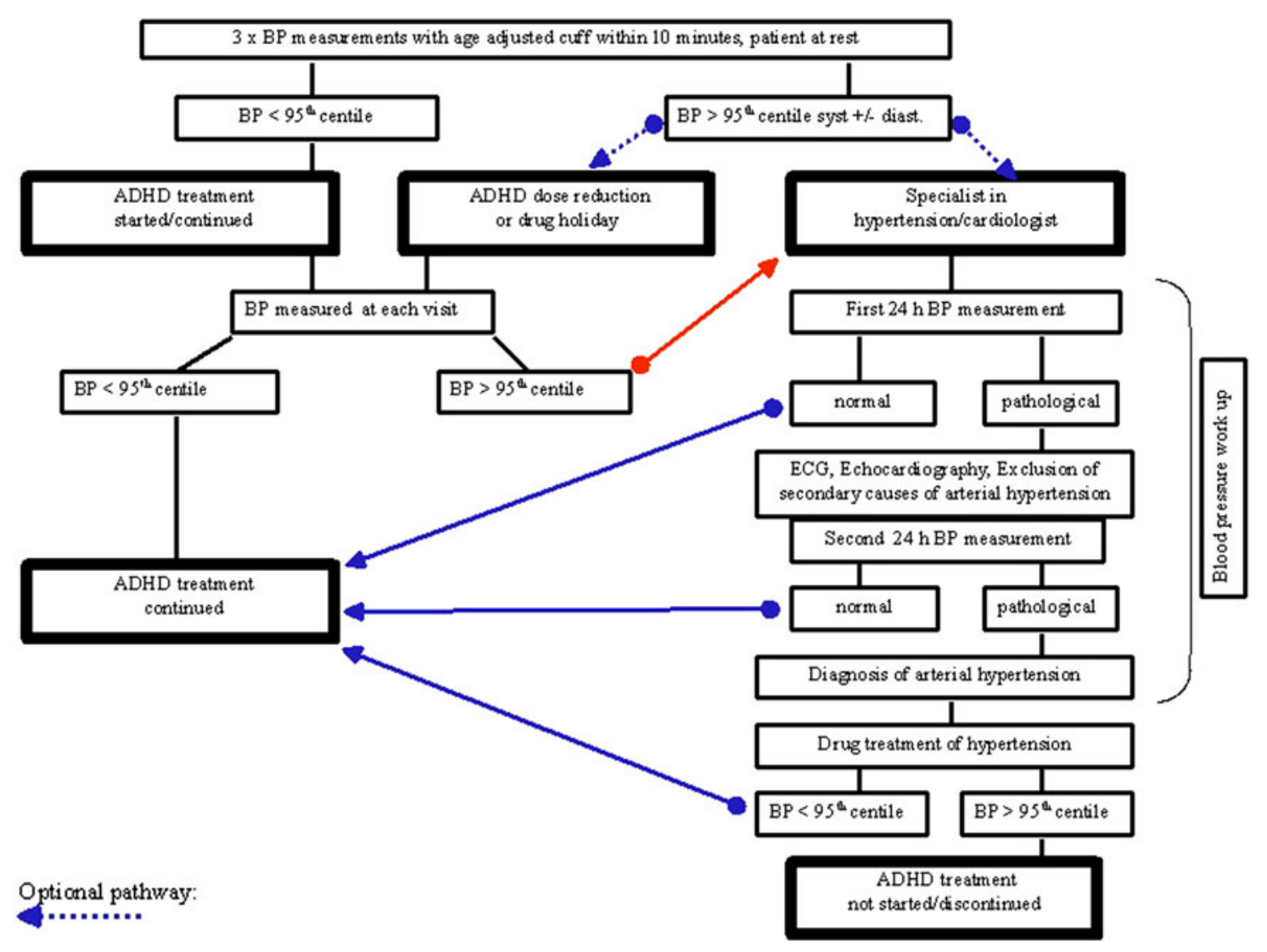

Fig. 1 Recommendation for blood pressure (BP) monitoring and management in ADHD patients

A pulse rate consistently above $120 / \mathrm{min}$ should be a signal for a cardiac review. New-onset palpitations should be managed as for unmedicated patients: occasional extra beats are not necessarily a cause for concern, but persistent tachycardia could be due to arrhythmia and needs investigation. In 2008 the American Heart Association initially recommended ECG as a standard part of the assessment for treatment for ADHD, prior to then changing this to be at the discretion of the clinician [147]. ECG screening is, however, not currently considered cost-effective or appropriate for prevention of sudden death in the general paediatric population in Europe (or the US), for example, as reported by Denchev et al. [32] in a recent economic evaluation of the issue. The issue of ECG in identification of at-risk individuals participating in competitive sport (also discussed by Denchev) is separate to the remit of this paper; and insufficient evidence exists to confirm the combination of ADHD medication and exercise as representing an increased risk. Our view in summary therefore is that there is no current evidence to suggest an incremental benefit for routine ECG assessment of ADHD patients prior to initiation of medication.

\section{Suicide-related events}

'Suicide-related events' are not only self-destructive acts but also include suicidal ideation, plans and beliefs in the pointlessness of life. It is generally accepted that an assessment of suicidality is an important part of psychiatric evaluation, either via general enquiry or via structured rating scales such as the Columbia suicide rating scale [111]; suicidal thoughts are not necessarily associated with a depressive disorder. Systematic review has indicated that there is a relationship between the presence of ADHD itself and suicidal attempts [161]; so it should not automatically be assumed that any suicidal thinking or attempt is an adverse effect of medication. In terms of severity and impact, most reports to the Multimodal Treatment Study of Children with ADHD (MTA) were of mild and transient symptoms that did not require hospitalisation [1]. There were no completed suicides.

Frequency of suicidality reports

Suicide-related events are rarely associated with ADHD drug treatment. Specific figures for stimulants are not publically available; however, summaries of product 
characteristic information for methylphenidate products do contain cautions about suicidality as a possible adverse effect.

In September 2005 the United States Food and Drug Administration (FDA) added a 'black box' warning to the product labelling of atomoxetine [Eli Lilly and Co., Strattera safety information, 2006 (online)], based on an analysis of adverse-event data from the atomoxetine clinical trials database, which identified a small but statistically significantly increased risk of suicidal thoughts among atomoxetine-treated children and adolescents compared with patients in those trials taking placebo. A meta-analysis of the data showed that suicidal ideation was more frequently observed in clinical trials among children and adolescents treated with atomoxetine $(5 / 1,357)$ compared to those treated with placebo $(0 / 851)$, with a number needed to harm (NNH) of 227 compared to the number needed to treat (NNT) of 5 to achieve remission of ADHD symptoms [15]. There was one suicide attempt in the atomoxetine-treated group and no completed suicide occurred during the trials. In adults treated with atomoxetine there was no evidence of increased suicidal risk.

Data from population-based studies indicate that selfreported suicide-related events are common in young people who have neither been diagnosed with, nor treated for, ADHD. For example, the rate of self-harm in UK 11-15 year olds with no mental disorder was $1.2,9.4 \%$ in those with anxiety disorders, $18.8 \%$ in children with depression, $12.6 \%$ in those with conduct disorder and $8.5 \%$ among children with hyperkinetic disorder [92]. In contrast, the prevalence of suicide-related behaviour in children treated with ADHD drugs from RCTs is reported as only $0.4 \%$ [144]. While this low observed event rate in trials is likely to reflect the exclusion of suicidal subjects from entering trials, a short time base, and a lack of systematic assessment and reporting, there is little or no compelling evidence to suggest that the observed event rate of suicide-related events in children treated with ADHD drugs is greater than the expected (background) rate in the general population.

\section{Causality and factors mediating risk}

Various emotional and behavioural changes are occasionally described in children treated with ADHD medications including: anxiety, agitation, panic attacks, insomnia, irritability, hostility, aggressiveness, impulsivity, akathisia (psychomotor restlessness), hypomania and mania. These could in principle be markers to the states of distress that can lead to suicidal acts; but no causal link between the emergence of such symptoms and the emergence of suicidal impulses has been established. Comorbidities occurring with $\mathrm{ADHD}$ (such as depression and conduct disorder) may in themselves be associated with an increase in the risk of suicidal ideation and/or behaviour.

Management of suicide risk

A psychiatric history is of course routinely needed before prescription of any medication. In view of uncertain degrees of risk, caution is required when prescribing ADHD drugs to children and young people with a past history of serious suicidal attempt or depression.

Families and caregivers should be advised of the need to recognise any emergence of emotional change or selfinjurious thinking; and to communicate well with the prescriber [144]. Patients being treated with ADHD drugs should be observed for the emergence of suicide-related events. If they do emerge in treatment, consideration should be given to dose reduction and/or other changes in the therapeutic regimen, including the possibility of discontinuing the medication; especially if these symptoms are severe or abrupt in onset, or were not part of the patient's presenting symptoms. Psychiatric evaluation (or re-evaluation) should be arranged and the patient's progress carefully monitored.

\section{Growth in childhood}

Poor growth is a common concern in the treatment of ADHD, especially with children already on the lower growth percentiles; but the impact of medication on growth in weight and height has remained somewhat unclear. There are outstanding questions as to whether ADHD in itself is an independent risk factor for poor growth, and whether individuals showing a slowing of growth whilst on medication return to their previous growth trajectory eventually or on discontinuation of medication.

Evidence of impact on growth, and possible causal mechanisms

Studies providing longitudinal data suggest that treating children with ADHD with stimulant medication generally results in a reduction in both height and weight gain [37, 112]. On average, the reduction in height amounts to approximately $1 \mathrm{~cm} /$ year during the first $1-3$ years of treatment [42]. The reduction in weight gain appears to be somewhat more pronounced than that for height (over a 3-year period about $3 \mathrm{~kg}$ less than predicted) [39, 139].

Stimulant treatment does not, however, appear to markedly increase the number of children who fall below the fifth percentile of the population [37]. Effects are usually minor, but there is substantial variability: some children are completely unaffected, whereas for others 
treatment results in significant growth suppression. Current data indicate that the initial effect of stimulants on growth appears to attenuate over time [39, 114, 139] and early studies of the adult outcomes of children treated with stimulant medications have suggested that final adult height is not affected [55, 71]. Nevertheless, follow-up periods are not yet sufficiently long enough, nor the sample sizes big enough, to allow firm conclusions to be drawn.

Most studies do not suggest differences in the magnitude of growth deficits between methylphenidate and dexamfetamine [108]. Small effects were seen for atomoxetine during the first 2 years of treatment; but in those who received prolonged treatment for up to 5 years no long-term effects on growth were apparent apart from an overweight subgroup $[133,134]$. These two parts of the same study are probably not yet sufficient evidence for ruling out growth problems as an adverse effect of atomoxetine, and indeed there is one study describing the medication as an effective adjunct to weight loss in obese women [45] (with similar studies examining similar outcomes for stimulants $[61,78])$.

It is possible that the effects of stimulants on growth are dose-dependent. Significant effects on weight and height may require average doses of methylphenidate exceeding $1.5 \mathrm{mg} /$ $\mathrm{kg}$ per day which are given continuously [28, 132]. Effects may be greater for children than adolescents, but overall there are too few studies to allow firm conclusions in either of these areas. Preschool children may be particularly vulnerable to growth effects: the National Institute of Mental Health Preschool ADHD Treatment Study reported that children between 3 and 5 years of age treated with methylphenidate had annual growth rates $20.3 \%$ less than expected for height $(1.38 \mathrm{~cm} /$ year $)$ and $55.2 \%$ for weight $(-1.32 \mathrm{~kg} /$ year $)$ [138].

\section{Causality and factors mediating risk}

Reduced caloric intake and suboptimal nutrition due to appetite suppression are likely causes of growth suppression. Hypothetically, dysregulation of receptors in the growth system could also be responsible; adaptation of receptors could contribute to tolerance to growth inhibition over time and to catch-up growth after the medication has been discontinued. Acute effects on growth hormone and prolactin have been observed, but do not yet explain persisting growth deficits [18, 37, 84]. A hypothesis that ADHD itself is associated with dysregulated growth, either decreased [54, 131] or increased [138, 139] has been put forward, but current evidence is contradictory.

\section{Management of growth risks}

Physicians should advise patients and their parents about the potential for growth delay with medication use and discuss the balance between these effects and the potential outcomes that may result from non-treatment. A growth chart should be used to monitor height, weight and appetite in all medication-treated children and adolescents at least 6 monthly [140]. Should growth deficits occur during treatment, various clinical strategies might be considered. Current data do not support specific guidelines indicating what magnitude of height or weight gain deceleration should trigger changes in the treatment regimen, but simple strategies to improve nutrition can be implemented. These may include coordinating the timing of doses (e.g. taking the first dose after breakfast) and meals (e.g. late evening meal) and encouraging the use of high-energy, nutritious snacks. These clinical strategies would be expected to reduce growth deficits, but no studies have yet examined this hypothesis directly. Periods of treatment cessation (drug holidays) seem to result in rebound growth for children who experienced deficits during treatment, with children seeming to return to their normal growth percentiles and trajectory [37, 112]. Drug holidays, however, can also be problematic for the child and family because the ADHD symptoms will often re-emerge or worsen during the period that medication is withheld. For individual patients, physicians need to balance the risk of exacerbating the child's ADHD symptoms, by lowering the dose or switching to a different medicine, against the risks associated with growth delays. Decisions should be based on the clinical considerations of the individual patient. If there is serious concern about growth, referral to a paediatric endocrinologist is warranted. Criteria for referral can follow the medical guidelines concerning referral for short stature and consideration of growth hormone supplementation in adults and children, which are as follows [46]:

- height $>1.5$ SDs below the average of mother's and father's height;

- height $>2$ SDs below the population mean plus a 1-year height velocity $>1$ SD below the mean or a 1 -year decrease of $>0.5$ SD in height;

- a 1-year height velocity $>2$ SDs below the mean, or a 2 -year height velocity $>1.5$ SDs below the mean.

Further research is needed into the causal mechanisms, and the long-term implications of continuous treatment from childhood to adulthood for ultimate height.

\section{Sleep disturbance}

As is the case for several of the other adverse events, an important initial point to make is that sleep disturbance may be associated both with ADHD medication, and the condition of ADHD itself. For example, a recent meta-analysis [31], based on 16 methodologically sound studies published between 1987 and 2008, showed that 
stimulant-free children with ADHD were significantly more impaired than healthy controls in parentally reported items of problematic behaviours around bedtime and in the early morning. These children were also impaired in some actigraphic and polysomnographic measures indicating fragmented sleep and poor sleep efficiency, sleep disordered breathing, and excessive daytime sleepiness [122]. However, the pooled analysis of all data on sleep architecture gave contradictory results about any alterations in REM sleep and no alterations on percentage of slow wave sleep. Some conditions associated with ADHD (such as anxiety) can also lead to poor sleep. The effect of sleep impairment differs greatly from one individual to another, but can be distressing to both the child and the family and may give rise to behavioural and learning difficulties in the daytime [103, 107].

Frequency of sleep problems

\section{Stimulants}

Clinical experience suggests that psychostimulant medication may negatively impact on sleep, but the effects vary considerably from one patient to another. An observational report suggested that some patients with ADHD are able to get to sleep easily within just a few hours of taking a dose of stimulant medication, others need an interval of up to 6-8 h [25]. However, a review of scientific studies comparing medicated and unmedicated children describes inconsistent outcomes, both for polysomnographic measures and for parental reports [123].

In a review of subjective reports on medicated versus unmedicated children with ADHD there were high rates of parental report of sleep problems, but few of these were confirmed by objective sleep data [29]. In a placebo-controlled cross-over actigraphic monitoring study of 44 children, sleep latency was similar in children with ADHD on methylphenidate versus placebo, but total sleep duration was shorter with methylphenidate than placebo [125]. However, a smaller, non-actigraphic study suggested that methylphenidate does not appear to affect sleep patterns adversely and possibly normalizes them in patients with ADHD [142].

Sleep problems may therefore primarily be related to ADHD severity and comorbidity and not to medication. Among individual sleep parameters, difficulty falling asleep continues to differ significantly between children with or without medication after the severity of ADHD symptoms has been controlled for [142].

\section{Nonstimulant medications}

In a randomized, double-blind, cross-over study comparing the effect of methylphenidate (given thrice daily) and atomoxetine (given twice daily) on the sleep of children with ADHD, methylphenidate increased sleep-onset latency significantly more than did atomoxetine, both considering actigraphic and polysomnographic data [123]. Moreover, both childrens' diaries and parents' reports indicated a better quality of sleep (in terms of "getting ready in the morning", "getting ready for bed", "falling asleep") with atomoxetine, compared with methylphenidate. Both medications decreased night-time awakenings, but the decrease was greater for methylphenidate. Clearly, these results from a single study need to be replicated.

\section{Causality and factors mediating risk}

Stimulants most likely increase wakefulness via their sympathomimetic action and as such are used in treatment of narcolepsy [2]. Several factors that may mediate the effects of stimulant medications on sleep have been identified. In one study, depressive symptoms contributed significantly to the degree of sleep disturbance when controlling for ADHD diagnosis and methylphenidate treatment [136]. Some studies assessed the effect of stimulants given in two doses (morning and noon). It is possible that sleep problems may be linked to restlessness linked to the rebound effect more than to the direct action of stimulants [26]. Some authors have reported that a small dose of methylphenidate taken before bedtime can facilitate sleep $[64,70]$. Other studies, however, using a third dose at the end of the day did find a greater sleep-onset delay in children treated with stimulants compared to untreated subjects [7, 137].

\section{Management of sleep problem risks}

Given the limited number of studies and the contradictory findings, guidelines for the management of sleep disturbances associated with ADHD cannot be properly evidence based. A history of any sleep problems should be taken before starting medication, and if this is a severe/significant issue, it may suggest atomoxetine as a first line choice. If problems arise during medication, then sleep diaries are recommended. Sleep hygiene and behaviour therapy techniques based on stimulus control, and appropriate bedtime scheduling, should be encouraged for children with sleep-onset problems and/or possible delayed sleep phase syndrome.

A switch of medication should be considered when sleep problems persist after careful dose adjustment and dosescheduling of the original medication; for instance, patients taking a stimulant medication might switch to atomoxetine. Although clonidine is outwith the main focus of this paper, some evidence exists to suggest it may be effective in ADHD with associated sleep problems [153]. Recent research has also shown that melatonin is effective in 
reducing sleep-onset problems in ADHD children and could be considered a reasonable therapeutic approach [17].

\section{Tics and Tourette's syndrome}

In tic disorders (TD), co-existence with ADHD can be found in about $50 \%$ of patients, while in ADHD patients a TD is seen in about 20\%: Both figures are above the chance rate of combination [121]. The use of licensed ADHD drugs (both stimulants and atomoxetine) in the presence of tics remains subject to debate. Some experts describe an increase in tics when drugs are given, others do not. Several physician's desk references and drug administration mandates still note a contraindication for the use of stimulants in patients with TD [110, 121]; and even in those with only a family history of tics. Fortunately, in recent updates this is no longer the case [49, 140], but taking a history of tics and close monitoring of coexisting tics are mandatory (see decision of the European Commission for a new wording of European Drug Administration Mandates being harmonized all over Europe, Homepage of EMEA 2009).

Several recent reviews [24, 119, 124] indicate that stimulants are adequately safe in patients with both ADHD and TD and should not be disregarded when planning treatment for ADHD in these individuals. In terms of the impact of TD, the psychosocial functioning of ADHD + TD children is usually not worsened significantly when tic exacerbation by drugs takes place, since ADHD is commonly the more impairing disorder [117, 118]. Rarely, stress-sensitivity may increase, but there will usually be enough time to come to a joint treatment decision with families balancing the risk-benefit ratio.

Frequency and causality

Dopamine-receptor antagonists may decrease tics, while drugs which increase dopamine activity may precipitate or exacerbate tics. The precipitation of first-onset tics during treatment with methylphenidate was found not to be different from placebo (range 0-20\%), according to a review that examined predominantly short-term studies, but included up to 4 years' duration of monitoring [119]. The literature on exacerbation of pre-existing tics by stimulants indicates that about $5-10 \%$ of cases may get worse with stimulants; independent of initial tic severity. This exacerbation, if it occurs, is fully reversible after stimulant withdrawal or dose reduction [104, 110]. Moreover, clinical experience suggests that with improvement of attention and self-regulation by stimulants the control of tics may itself improve. In the controlled studies of atomoxetine, its impact on tics was either not different from placebo or even showed some positive effect on tic frequency [8, 110, 135]. On the other hand, a few case reports have described exacerbation of tics during atomoxetine treatment [43, 77, 79, 105, 106, 126]. This might reflect dopamine imbalance in certain patients, which is in line with the theory that stimulants might lead to further activation of an already hyperactive meso-striatal dopaminergic system in TD, where higher doses of stimulant compounds may provoke a higher frequency of tics.

\section{Management of tics during ADHD treatment}

Because tics are naturally waxing and waning, it is often difficult to decide if a worsening of tics is provoked by a drug. Therefore, a long-term observation of at least 3 months is sometimes required before a clinical decision can be made. ADHD and TD can be considered within the framework of an additive model [14, 121]. It follows, that the symptoms may be treated with a separate but parallel approach, i.e. in addition to stimulants or atomoxetine for ADHD, treatment with antipsychotic medication may help to reduce tics. The latter suggestion is not evidence based, being derived from the experiences of clinical experts only; but meanwhile it has been included in clinical guidelines [120]. It can be assumed that the effect on tic exacerbation is similar for both methylphenidate and dexamfetamine. For atomoxetine, however, the situation may be more favourable, although the negative case reports cannot be neglected. For clonidine, which is only occasionally used in Europe to treat TD and/or ADHD, but recommended by some authors (especially where TD is the predominant disorder) [116], there exists some evidence that it may reduce tics in frequency and severity, as well as improve ADHD symptoms; but on the other hand, worsening of tics may be seen in about a quarter of cases [3].

\section{Substance abuse, misuse and diversion}

Substance use disorder (SUD) is a maladaptive pattern of non-medical use of substances leading to functional impairment and/or risks over the past 12 months. Substance dependence is differentiated from abuse by the presence of drug tolerance, preoccupation with drug seeking and drug taking, and continued use despite knowledge of risks and despite repeated attempts to stop (as opposed to simply use associated with various risks and actual harms). Concurrence of ADHD and SUD has been consistently observed for many years and there is an ongoing debate on the question whether medication treatment of ADHD, with stimulants in particular, changes the risk for patients to develop SUD. Concerns exist both as to 
the use of stimulants to achieve a 'high' or for other reasons, such as to aid weight loss (misuse), and also as to the use of medications by individuals for whom they were not specifically prescribed (diversion). Findings from preclinical research have suggested that animals exposed to stimulants become "sensitized": subsequent administration results in more robust behavioural responses, and/or they become more likely to self-administer drugs of abuse later in development $[72,73]$.

Comorbid risk and estimates of frequency of abuse

Several epidemiological studies compare ADHD subjects with unaffected groups, and find hazard ratios for SUD varying from 1.2 to 3 [22, 35, 95] and up to 7.9 for drug dependence [68]. Even a single symptom of ADHD or conduct disorder (CD) may be associated with an increased risk for SUD [35]: hyperactivity symptoms uniquely contributed to subsequent initiation of all types of substance use, to nicotine dependence, and cannabis abuse/dependence, even after controlling for $\mathrm{CD}$, whereas impulsivity predicted alcohol misuse [36]. Based on follow-up data from the MTA study, significantly higher rates of childreported lifetime substance use at age 13 were reported in ADHD patients compared to a local normative comparison group (HRs 2.3) [94]. Probands with ADHD who did not differ from those without ADHD in absolute rates of SUD, still had an earlier onset, a longer duration, and higher rates of severely impairing SUD as well as higher rates of alcohol and drug dependence than non-ADHD children [23]. Correspondingly, the prevalence of childhood and adult ADHD in the substance-abusing population has been estimated to be about 3 times that in the general population: for instance, adults with a lifetime diagnosis of cocaine and/or opioid dependency show an ADHD lifetime prevalence of $5.2 \%$, compared to $0.85 \%$ in individuals without SUD [10].

Do stimulants increase the risk of SUD?

Whether stimulant medication adds to the risk for substance abuse is not clear; several studies suggest it does not. A meta-analytic review of six studies suggested that stimulant therapy in childhood may be associated with a reduction in risk, compared to unmedicated ADHD subjects, for subsequent drug and alcohol use disorders $(\mathrm{HR}=1.9)$, with a stronger effect during adolescence $(\mathrm{HR}=5.8)$ than adulthood follow-up $(\mathrm{HR}=1.4)$ [155]; however, when this group was re-examined a further 5 years later no significant differences were found that might represent a difference in substance use risk [21]. The reduction in risk might be attributable to treatment rather than stimulant medication in particular: the MTA study found a reduction in risk for those patients treated with behaviour therapy; medication had no effect one way or the other [94]. No difference in substance use was observed in patients with developmental reading disorder (but without ADHD), previously treated with methylphenidate or placebo for up to 18 weeks, suggesting that neither sensitization nor protective effects can be related to stimulant treatment per se [85]. Other studies show either no influence of methylphenidate or a reduction of risk; in one study only when stimulant treatment had been initiated before puberty $[21,38,53,65,86]$.

\section{Putative mediating processes}

With regard to potential mediating factors, gender and the presence and severity of $\mathrm{CD} / \mathrm{antisocial}$ personality disorder or delinquency appear to be the moderating variables for the risk of subsequent SUD in ADHD patients; and these effects are stronger than any influence of medication [16]. In ADHD subjects, both genetic predisposition and social/ environmental factors interact to determine persistence of conduct symptoms and antisocial behaviours [27, 101, 129], which are then important influences on substance abuse and misuse.

Euphoric properties and reinforcing effects of methylphenidate are associated only with intravenous injection or nasal inhalation and not with oral administration [148]. Euphoria is practically unknown with oral methylphenidate; though the situation with dexamfetamine is unclear, because of lack of study rather than conflicting findings. Misuse or diversion of stimulants has been reported in adolescents and young adults in North America, either in order to improve academic performance (studying, staying awake, improved alertness) or in the context of a SUD $[145,152,156]$.

Prevention and management of comorbid SUD, misuse and diversion

Early recognition and treatment, perhaps combined with longer term behaviour therapy and/or longer term/continuous medication treatment, may reduce the risk for SUD in ADHD patients. Depending on the specific situation, current or previous substance abuse in the family can be seen as either a relative contraindication for stimulant prescription, especially in the immediate release preparation, or as a reason for extremely close monitoring of a patient's stimulant use. The extended-release formulations of stimulants are less prone to diversion because these preparations cannot easily be crushed into powder for injection or snorting, and also because the once-a-day administration makes parental supervision easier to enforce. Based on preclinical, short-term clinical data and abuse liability 
studies, the noradrenergic compound atomoxetine does not appear to be associated with risk for substance use disorders and may well be preferred in high-risk cases [63].

Use of cannabis is not necessarily a contraindication to prescribing stimulant medication, and a pragmatic approach will be required. The other dangers of cannabis, however, should not be ignored and patients will need to be warned of these. Cocaine, however, is likely to be a real hazard in view of its sharing neurochemical effects with dopaminergic drugs, and the two should not be combined.

\section{Epilepsy and seizures}

Children with epilepsies show a 3- to 5-fold higher prevalence of ADHD than controls [33]. Among the various psychopathological features of the epilepsies, ADHD is the most frequent comorbidity. ADHD patients have been shown to have incidence rates of unprovoked seizures and epilepsy as many as two to three times greater than non-ADHD children [58]. Although epileptic disorders affect $\sim 1 \%$ of the paediatric population, the evidence base for ADHD treatment in children with epilepsies is disproportionately thin.

There are occasionally concerns that, as with other psychotropics, ADHD medications may lower the seizure threshold so as to cause seizures in previously seizure-free individuals. However, in prospective trials, retrospective cohort studies and post-marketing surveillance in ADHD patients without epilepsies, the incidence of seizures did not differ between ADHD pharmacotherapy and placebo [relative risk (RR)] for current versus non-use for methylphenidate, 0.8; RR for atomoxetine, 1.1 [90, 151]. Methylphenidate has been shown to prolong the duration of kindled seizures in rats [11]. Amfetamine has the potential to both increase and decrease seizure risk in animals [50, 69]. In rodents treated with atomoxetine, seizure induction occurred only with doses several-fold higher than the highest approved dose for humans [143].

\section{Mediating influences}

Higher overall seizure rates are reported from untreated ADHD patients with epilepsy compared to similar but medication-treated ADHD patients [90]; it is unclear whether this is due to a reluctance to administer ADHD medication to children at risk for epilepsy or to risk factors mitigated by ADHD treatment (e.g. substance abuse). An elevated risk for seizures can be associated with antiepileptic drug (AED) polypharmacy, mental retardation, neurologic deficits, metabolic diseases, congenital anomalies, and other developmental disorders [90]. Available evidence does not support an increased risk in seizure-free ADHD children with centrotemporal (rolandic) spikes [56, 59].
Differential drug effects

There is substantial evidence for short-term efficacy of methylphenidate in children with epilepsies, while no negative effects on seizures and EEG abnormalities have been observed, and indeed there is some evidence for possible benefits in some cases [42, 51, 52]. A larger systematic review did not find evidence for meaningful pharmacokinetic or pharmacodynamic interactions between methylphenidate and AEDs [87]. For amfetamine, effects on comorbid ADHD and epilepsies are not yet systematically evaluated. Response rates in case series reports are disappointing, but these reports are biased since they almost exclusively included nonresponders to methylphenidate $[47,102]$. Amfetamine seems to have an anticonvulsant effect in patients with nocturnal seizures and a favourable impact on drowsiness induced by AEDs [9, 41, 82]. In several retrospective case series reports of previous methylphenidate non-responders with epilepsy, atomoxetine showed disappointing response rates and high rates of discontinuation [143]. Limited evidence from prospective case series reports in children with epilepsy is more promising, but a seizure increase may occur in a minority of cases [57]. For amfetamine and atomoxetine, efficacy and short-term safety have yet to be established in stimulantnaive patients with infrequent seizures. As with methylphenidate, preliminary evidence supports efficacy on ADHD symptoms and a low seizure risk in patients with infrequent seizures. Studies in children with more active epilepsy seem justified.

\section{Management of seizure risks}

Adolescents with epilepsies are at increased risk for depression and suicidal ideation [12]. During ADHD treatment, they should therefore be monitored for the emergence of depression, irritability and suicidal ideation. A careful evaluation of the potential benefits and risks of pharmacotherapy seems warranted in preschool ADHD children, in whom epilepsies may still be recognised for the first time during their further development. Fatal hepatotoxicity has been reported as an extremely rare event in young epileptic children with polypharmacy or inborn errors of metabolism. Regarding the combination of atomoxetine with antiepileptic agents that might increase the risk for liver toxicity, patients should be carefully monitored clinically. Elevation of liver enzymes, however, is a poor predictor of impending hepatotoxicity.

Besides specific pharmacotherapy, it has been shown that symptoms of inattention, impulsivity and restlessness in epilepsy may be improved by non-specific interventions, such as better seizure control, decreasing AED polypharmacy, reducing drug interactions, and switching to AEDs with fewer cognitive and behavioural effects [143]. 


\section{Psychotic symptoms}

The term 'psychosis', as a reported adverse event, is defined at the level of symptoms and does not imply a full-blown psychotic disorder. Psychotic symptoms include hallucinations or delusions occurring in clear consciousness, neither associated with fever nor transitions to or from sleep. Adverse-event reporting of 'psychosis' frequently also includes symptoms of mania, hypomania and 'agitated states'. In terms of the severity of impact of these symptoms, most reports from the FDA analysis described below [96] were of mild and transient symptoms that did not require hospitalisation or treatment.

\section{Frequency}

Data from population-based birth cohorts indicate that selfreported psychotic symptoms are common and may occur in up to $10 \%$ of 11-year-old children [115]. In contrast, the prevalence of psychotic symptoms in children treated with ADHD drugs from RCTs is reported as only 0.19\% [39]. While this very low observed event rate in trials is likely to reflect a lack of systematic assessment and reporting, there is no compelling evidence to suggest that the observed event rate of psychotic symptoms in children treated with ADHD drugs exceeds the expected (background) rate in the general population. In the US FDA analysis, ADHD drug overdoses did not contribute significantly to reports of psychosis adverse events.

Psychotic symptoms are rarely associated with ADHD drug treatment. The United States Food and Drugs Administration (FDA) [96], reviewed 49 RCTs of ADHD drugs in children and found a total of 11 psychosis/mania events during 743 person-years of exposure with ADHD drug treatment compared to no psychosis events reported with placebo. From these data, the psychosis event rate is 1.48 per 100 person-years, or one event in every 70 years of treatment with a number needed to harm $(\mathrm{NNH})$ of 526.

The FDA also reviewed industry post-marketing surveillance case reports in the United States for ADHD drugs prescribed in children and adults between 2000 and 2005 and found 865 reports of psychosis events [144]. Half of these reports occurred in children under the age of 10 years. Although the exact denominator (prescribing frequency) is unknown for post-marketing surveillance reports, if we assume a prescribing frequency of 3 per 100 school age children in the United States this results in a rate of reported psychosis events of 1 in 2,500 treated cases of ADHD.

Psychotic adverse events have been reported in association with dexamfetamine, methylphenidate, and atomoxetine. The FDA review of ADHD drug RCTs, with regard to the ADHD drugs reviewed in this report, reported the highest psychosis adverse event rate with MPH (in the form of transdermal patches, not currently licensed in Europe) (13.2/100 person-years) followed by dexamfetamine $(2.0 / 100$ person-years $)$ and atomoxetine $(0.8 / 100$ person-years). No psychosis adverse events were reported in 11 RCTs of oral methylphenidate (immediate and modified release) and 4 RCTs of mixed amfetamine salts (Adderall XR).

\section{Mediating mechanisms}

Amfetamine increases synaptic release of dopamine in the mesolimbic system and is associated with increased positive psychotic symptoms in patients with schizophrenia [76]. Hence, there is a plausible neurobiological mechanism that could link stimulant drugs with psychotic symptoms. However, this evidence all comes from studies in adults and in those with a pre-existing psychotic disorder and consequent increased vulnerability to psychotic symptoms. It is unclear whether a similar risk applies to children and those without an increased biological vulnerability to psychosis. Interestingly, half of the US FDA post-marketing surveillance reports of psychotic symptoms occurred in young children (under age 10) who would typically be viewed as being less vulnerable to dopaminemediated drug-induced psychosis than adolescents or adults [39].

Theoretically, at least, evidence of vulnerability to psychosis in terms of a positive family history or prior psychotic episodes may increase the risk of psychotic symptoms with ADHD drugs.

\section{Management of risk of psychosis or mania}

The evidence of an increased risk of psychotic symptoms associated with ADHD medications is weak. Reported psychosis adverse events are rare and much less common than the expected rate of self-reported non-clinical psychotic symptoms in the general child population. The impact of reported psychosis adverse events in most cases is mild and most are self-limiting. If psychotic symptoms do occur with ADHD drugs, then they could in very rare circumstances represent an adverse drug reaction or symptom of a psychotic disorder, but consideration should be given to the more likely possibility that psychotic symptoms are common phenomena in children and in most circumstances will be unrelated to either ADHD drugs or a psychotic disorder. Nevertheless, and in view of potentially increased vulnerability to psychosis with ADHD drugs, caution would be appropriate when prescribing ADHD drugs to children and young people with a family history of psychosis or past history of psychotic episodes. 


\section{Drug holidays: a way of controlling adverse effects of ADHD drugs?}

The structured interruption of a pharmacological treatment (often called a drug holiday) occurs when a patient stops taking medication(s) for a period of time. In general, drug holidays can be very short (a few days) or very long (months or even years). Drug holidays are commonly used in a range of therapeutic domains. Clinical anecdote and informal report suggests to us that drug holidays are quite commonly used in relation to ADHD medication. Drug holidays can have various functions, and in relation to ADHD treatment these can be divided into four types.

First, drug holidays anecdotally have been used to counteract waning effectiveness after a period of continuous use; perhaps by interrupting the development of possible tolerance and/or the need to continually increase the dose over time. Second, they can be used to monitor whether medication is still effective after a period of longterm treatment or whether the balance between side effects and therapeutic effects is still in favour of continued treatment. Third, they can be used to allow 'normal' life to resume either for activities to be undertaken without the effects of symptom control being apparent-some individuals prefer to not take medication to be 'themselves', to play sport, etc.- or for there to be no need to remember to take tablets. Finally, drug holidays can be used to control acute adverse events (e.g. poor sleep and reduced appetite) and reduce their chronic effects (e.g. reduced growth or long-term increases in blood pressure).

Despite the potential value of drug holidays and the likelihood that they are used frequently, either formally or informally, as part of ADHD medication regimen, there is very little data on issues such as the extent of their use; the factors that predict use (e.g. child characteristics, parent and clinician's beliefs, disorder progression, social structures and cultural norms); or their effectiveness in terms of either enhancing or reducing clinical effects or reducing side effects and their adverse consequences.

Systematic study of these three questions seems especially important now because not only has consideration of drug holidays been recommended on pragmatic grounds $[37,113,140]$, but also because of their potential frequent use; especially as parents (and/or patients) may often initiate drug holidays independently without the clinical guidance or approval $[60,89,154]$.

Evidence for drug holidays

In the only randomized controlled trial addressing the issue of drug holidays and ADHD drug adverse effects, patients were randomized to receive either BID methylphenidate 7 days a week or 5 days a week and a weekend drug holiday when placebo was administered in a double-blind design [89]. No reduction in therapeutic effects on weekends (as rated by parents) or on the following day of school (as rated by teachers) was found, but despite this, fewer sleep and appetite side effects were reported. Observational studies have also focused on the longer term effects of drug holidays on growth. A study on the effects of long-term (at least 21 months) use of OROS methylphenidate on the growth of children and adolescents reported relatively small effects of methylphenidate on overall height and weight and a slight beneficial effect of drug holidays; however, these effects were not significant [132]. In a similar study comparing amfetamine and methylphenidate in children treated for at least 1 year, small effects of drug dose were found on height and weight but there was no effect of the duration of treatment or the use of drug holidays [55].

\section{Risk-benefit balance}

The risk-benefit balance of drug holidays must be taken into account, and there are risks attached to the intermittent cessation of treatment. For instance, a review of the relationship between ADHD and burn accidents reported that a high proportion of children visiting burns units had not had their usual dose of medication on the day of the visit [44, 141]. Furthermore, the health economic costs per year to accident emergency departments were higher when children were not receiving their normal medication [80].

In summary to date, and despite their theoretical benefits, the evidence that drug holidays can help control side effects is very limited. The database needs to be expanded in a number of ways. First, the Martins et al. [89] findings of the possible benefits of 5-days-a-week administration need to be replicated; second, longer term studies need to be conducted using randomized and quasi-randomized designs; third, the range of adverse effects studied in relation to drug holidays needs to be extended (to include for instance cardiac effects). Fourth, the differential impact of 'informal' parent/patient-initiated and 'formal' clinician-initiated holidays should be studied. Fifth, the predictors of drug holiday effectiveness need to be examined. Sixth, benefits and costs of drug holidays need to be assessed systematically.

\section{Issues lacking evidence and future evidence sources}

A recurring theme in this paper is that there is particular uncertainty about possible adverse effects that are rare and severe. The most extreme is sudden death; which, as considered above, is so uncommon that extremely large numbers of subjects will be needed to detect whether the 
risk is raised above the base rate in the general population. Liver failure presents a similar uncertainty for the clinician: rare cases have been reported in people taking atomoxetine. They may well be no more common than in the population as a whole, but no conclusion is possible. The probability of under-reporting, and the lack of information about the usual prevalence of otherwise unexplained liver failure, leave real uncertainty. We can recommend only that the clinician should be vigilant for early signs of disease-which would include persistent and unexplained malaise as well as the more obvious features such as jaundice, dark urine, or itching-and investigate with liver enzyme tests if they appear. In the UK, the former Committee on Safety of Medicines has stated that families should be warned in advance of the necessity for medical advice if any of these signs should appear.

Another kind of uncertainty arises from possible problems for which good measurement has not previously been available. There could be long-term changes in the brainfor instance, in neurotransmitter levels or receptor density — but adequate techniques of investigation are only now becoming available. We do not know if such changes occur; if they do, whether they are related to medication or to the condition itself; if they are caused by medication, whether they have functional significance; and whether any changes are helpful or harmful to mental development. This is not to argue that the effects are harmful; to the contrary, our clinical experience of long-term medication has not uncovered concerns of cognitive malfunction or brain damage. Rather, it is to point to the need for research on possible subtle changes, whether for good or for ill. Neuropsychological instruments should be developed to test specific hypotheses about potentially harmful effects. New techniques are appearing that could in principle allow prediction of individuals' vulnerability to adverse effects. Pharmacogenomics, repeated monitoring of blood levels of ADHD compounds, and neuroimaging of the brain's response to medication could all earn a place in clinical practice. For the moment, however, we see them as opportunities for translational research, not recommendations for practice.

For many clinicians, the balance of risk against possible benefits of treatment will be seen as favourable in most cases, but with a caveat that there are several areas of uncertainty about the nature of these risks. This review should help in this regard, but as already discussed each area still requires further clarification from pharmaco-epidemiology. The concept of 'willingness to pay' may have value when applied to the question of what level of adverse effects is acceptable for a given treatment benefit for an individual person. Responsive discussion with patients and their families is important. Monitoring should include not only the blood pressure and growth measures already mentioned, but also common symptoms such as headache, insomnia, anorexia, nausea and emotional upsets; and any specific problems emerging in the individual patient. As ever, the primary responsibility for ensuring the safety of the patient lies with the prescriber.

\section{Conflict of interest}

Prof T. Banaschewski: Speakers Bench fee: Lilly, Janssen McNeil, Medice, Novartis, UCB. Advisory Board/consultancy: Desitin, Lilly, Medice, Novartis, Pfizer, Shire, UCB and Vifor Pharma. Research grants: Lilly, Shire and Novartis; unrestricted grants educational: Lilly, Janssen McNeil, Medice, Novartis, Shire, UCB.

Prof. J. Buitelaar: Speakers Bench fee: Lilly, JanssenCilag, Medice. Advisory Board: Lilly, Janssen-Cilag, UCB, Organon, Shire, Pfizer, Otsuka/BMS. Research grant: Lilly, Janssen-Cilag.

Dr. D. Coghill: Speakers Bench fee: Shire, Janssen Cilag, Medice, Lilly, UCB and Flynn Pharma. Advisory boards and/or consultancy: Shire, Janssen Cilag, SheringPlough, Pfizer, Lilly, UCB and Flynn Pharma. Research grants: Lilly and Shire.

Prof. M. Danckaerts: Speakers Bench fee: Lilly, UCB, Medice, Shire, Novartis. Advisory Board: Lilly, UCB, Shire, Pfizer. Consultancy: Novartis. Research Grant: Lilly, Janssen Cilag, Shire.

Prof. Ralf Dittmann: Speakers Bench fee: regional nonprofit advocacy group. Advisory Board: Lilly. Consultancy: Janssen, Lilly, Shire, Organon. Research grant: Lilly, Shire, German Ministry of Education and Research, European Commission (FP 7).

Prof. M. Döpfner: Speakers Bench fee: Medice, Shire, Lilly, Janssen-Cilag, Novartis, Advisory Board: Medice, Shire, Lilly, Novartis, Vifor. Consultancy: Medice, Shire, Lilly, Novartis, Astra Zeneca, Vifor. Research grant: Medice, Shire, Lilly, Vifor. Royalties Hogrefe Publishing, Beltz Publishing.

Dr. J. Graham: Speakers Bench fee: Lilly, UCB. Conference attendance: Janssen, Lilly, Shire, UCB.

Dr. R. Hamilton: Research grant: CIHR, Heart and Stroke Foundation, Catilyn Elizabeth Morris fund.

Prof. Ch. Hollis: Speakers Bench fee: Lilly, Janssen, Shire. Advisory Boards: Lilly, Janssen, Shire and Flynn PharmaI. Research grants: Wellcome Trust, NIHR and the Health Foundation, MRC. Royalties: Blackwell.

Prof. M. Holtmann: Speakers Bench fee: Lilly, Astra Zeneca, Novartis, Shire, Bristol-Myers Squibb and Neuroconn. Advisory Board: Lilly, Novartis, and Bristol-Myers Squibb, Consultancy: Astra Zeneca, Research grant: German Research Federation.

Dr. M. Hulpke-Wette MD: no conflict of interest. 
Prof. M. Lecendreux: Consultant: Shire, UCB. Research Grants: Lilly, Shire

Dr. E. Rosenthal: Consultancy Schwarz Biosciences Inc.

Prof. A. Rothenberger: Speakers Bench fee: Lilly, Shire, Medice, Novartis. Advisory Board:

Lilly, Shire, Medice, Novartis. Research Grants: Shire, German Research Society, Schwaabe. Travel Support: Shire.

Dr. P. Santosh. No conflict of interests.

Prof. J. Sergeant: Speaker's Bench Fee: Shire, Lilly, Janssen-Cllag. Advisory Board: Lilly, Shire. Research Grant(s) Lilly; unrestricted educational grants: JansenCilag, Lilly, Medice, Novartis UCB, Shire.

Prof E. Simonoff: Speakers Bench fee: University of Oxford. Trends in Psychiatry Research, Association for Child and Adolescent Mental Health, Advisory Board: Food Standards Agency, Mental Capital and Wellbeing Project. Writing: The Medicine Publishing Company, Maria Ugdom Clinic.

Prof. E. Sonuga-Barke: Speaker's Fee, Jannsen Cilag, UCB, Shire, Novartis. Advisory Board: UCB, Shire, Flynn, Astra Zenika. Consultancy: UCB, Shire. Research Grant: Janssen Cilag, UCB, Shire, Flynn, Qb-tec, Lilly. Royalties Jessica Kingsley, Oxford University Press.

Prof. H.-Ch. Steinhausen: Speaker's Bench fee: JanssenCilag, Eli Lilly, Novartis, Medice, Shire, and UCB Advisory Board Janssen-Cilag, Eli Lilly, Novartis, Medice, Shire, and UCB. Unrestricted grants postgraduate training courses and conferences: Janssen-Cilag, Eli Lilly, Novartis, Medice, and Swedish Orphan International. Research grant: Janssen-Cilag, Eli Lilly, Novartis, Medice, and Swedish Orphan International.

Prof. E. Taylor: Consultancy: Trusteeship of child charities, unpaid, Royalties: Blackwells, Random house, Mackeith Press.

Prof. I. Wong: Speakers Bench fee: Janssen-Cilag (School of Pharmacy received the fee), Consultancy: Brintnall and Nicolini, Inc. Research grant: National Institute of Health Research in England, Shire, European Commission.

Dr. Zuddas: Speakers Bench fee: Lilly, Shire, SanofiSynthelabo. Research grants; Lilly, Shire Consultancy: Lilly, Shire, UCB, Bristol-Myer Squibb/Otsuka, ScheringPlough Astra Zeneca; Conference support: Eli Lilly, Shire and Sanofi-Synthelabo.

Open Access This article is distributed under the terms of the Creative Commons Attribution Noncommercial License which permits any noncommercial use, distribution, and reproduction in any medium, provided the original author(s) and source are credited.

\section{References}

1. (1999) A 14-month randomized clinical trial of treatment strategies for attention-deficit/hyperactivity disorder. The MTA Cooperative Group. Multimodal Treatment Study of Children with ADHD. Arch Gen Psychiatry 56:1073-1086
2. (2001) Methylphenidate and narcolepsy: new indication. When modafinil fails. Prescrire Int 10:7-9

3. (2002) Treatment of ADHD in children with tics: a randomized controlled trial. Neurology 58:527-536

4. (2004) The fourth report on the diagnosis, evaluation, and treatment of high blood pressure in children and adolescents. Pediatrics 114:555-576

5. Aagaard L, Weber CB, Hansen EH (2010) Adverse drug reactions in the paediatric population in Denmark: a retrospective analysis of reports made to the Danish Medicines Agency from 1998 to 2007. Drug Saf 33:327-339

6. Abikoff HB, Vitiello B, Riddle MA, Cunningham C, Greenhill LL, Swanson JM, Chuang SZ, Davies M, Kastelic E, Wigal SB, Evans L, Ghuman JK, Kollins SH, McCracken JT, McGough JJ, Murray DW, Posner K, Skrobala AM, Wigal T (2007) Methylphenidate effects on functional outcomes in the preschoolers with Attention-Deficit/Hyperactivity Disorder Treatment Study (PATS). J Child Adolesc Psychopharmacol 17:581-592

7. Ahmann PA, Waltonen SJ, Olson KA, Theye FW, Van Erem AJ, LaPlant RJ (1993) Placebo-controlled evaluation of Ritalin side effects. Pediatrics 91:1101-1106

8. Allen AJ, Kurlan RM, Gilbert DL, Coffey BJ, Linder SL, Lewis DW, Winner PK, Dunn DW, Dure LS, Sallee FR, Milton DR, Mintz MI, Ricardi RK, Erenberg G, Layton LL, Feldman PD, Kelsey DK, Spencer TJ (2005) Atomoxetine treatment in children and adolescents with ADHD and comorbid tic disorders. Neurology 65:1941-1949

9. Appleby JG (1985) Use of dextroamphetamine in epilepsy. J S C Med Assoc 81:281-282

10. Arias AJ, Gelernter J, Chan G, Weiss RD, Brady KT, Farrer L, Kranzler HR (2008) Correlates of co-occurring ADHD in drugdependent subjects: prevalence and features of substance dependence and psychiatric disorders. Addict Behav 33:11991207

11. Babington RG, Wedeking PW (1973) The pharmacology of seizures induced by sensitization with low intensity brain stimulation. Pharmacol Biochem Behav 1:461-467

12. Baker GA (2006) Depression and suicide in adolescents with epilepsy. Neurology 66:S5-S12

13. Banaschewski T, Coghill D, Santosh P, Zuddas A, Asherson P, Buitelaar J, Danckaerts M, Dopfner M, Faraone SV, Rothenberger A, Sergeant J, Steinhausen HC, Sonuga-Barke EJ, Taylor E (2006) Long-acting medications for the hyperkinetic disorders: a systematic review and European treatment guideline. Eur Child Adolesc Psychiatry 15(8):476-495

14. Banaschewski T, Neale BM, Rothenberger A, Roessner V (2007) Comorbidity of tic disorders and ADHD: conceptual and methodological considerations. Eur Child Adolesc Psychiatry 16(Suppl 1):5-14

15. Bangs ME, Tauscher-Wisniewski S, Polzer J, Zhang S, Acharya N, Desaiah D, Trzepacz PT, Allen AJ (2008) Metaanalysis of suicide-related behavior events in patients treated with atomoxetine. J Am Acad Child Adolesc Psychiatry 47:209-218

16. Barkley RA, Fischer M, Smallish L, Fletcher K (2003) Does the treatment of attention-deficit/hyperactivity disorder with stimulants contribute to drug use/abuse? A 13-year prospective study. Pediatrics 111:97-109

17. Bendz LM, Scates AC (2010) Melatonin treatment for insomnia in pediatric patients with attention-deficit/hyperactivity disorder. Ann Pharmacother 44:185-191

18. Bereket A, Turan S, Karaman MG, Haklar G, Ozbay F, Yazgan MY (2005) Height, weight, IGF-I, IGFBP-3 and thyroid functions in prepubertal children with attention deficit hyperactivity disorder: effect of methylphenidate treatment. Horm Res 63:159-164 
19. Berenson GS, Srinivasan SR, Bao W, Newman WP III, Tracy RE, Wattigney WA (1998) Association between multiple cardiovascular risk factors and atherosclerosis in children and young adults. The Bogalusa Heart Study. N Engl J Med 338:1650-1656

20. Berger S, Utech L, Fran Hazinski M (2004) Sudden death in children and adolescents. Pediatr Clin North Am 51:1653-1677

21. Biederman J, Monuteaux MC, Spencer T, Wilens TE, Macpherson HA, Faraone SV (2008) Stimulant therapy and risk for subsequent substance use disorders in male adults with ADHD: a naturalistic controlled 10-year follow-up study. Am J Psychiatry 165:597-603

22. Biederman J, Petty CR, Dolan C, Hughes S, Mick E, Monuteaux MC, Faraone SV (2008) The long-term longitudinal course of oppositional defiant disorder and conduct disorder in ADHD boys: findings from a controlled 10-year prospective longitudinal follow-up study. Psychol Med 38:1027-1036

23. Biederman J, Petty CR, Wilens TE, Fraire MG, Purcell CA, Mick E, Monuteaux MC, Faraone SV (2008) Familial risk analyses of attention deficit hyperactivity disorder and substance use disorders. Am J Psychiatry 165:107-115

24. Bloch MH, Panza KE, Landeros-Weisenberger A, Leckman JF (2009) Meta-analysis: treatment of attention-deficit/hyperactivity disorder in children with comorbid tic disorders. J Am Acad Child Adolesc Psychiatry 48:884-893

25. Brown TE, McMullen WJ Jr (2001) Attention deficit disorders and sleep/arousal disturbance. Ann NY Acad Sci 931:271-286

26. Carlson GA, Kelly KL (2003) Stimulant rebound: how common is it and what does it mean? J Child Adolesc Psychopharmacol 13:137-142

27. Caspi A, Langley K, Milne B, Moffitt TE, O’Donovan M, Owen MJ, Polo, Tomas M, Poulton R, Rutter M, Taylor A, Williams B, Thapar A (2008) A replicated molecular genetic basis for subtyping antisocial behavior in children with attention-deficit/ hyperactivity disorder. Arch Gen Psychiatry 65:203-210

28. Charach A, Figueroa M, Chen S, Ickowicz A, Schachar R (2006) Stimulant treatment over 5 years: effects on growth. J Am Acad Child Adolesc Psychiatry 45:415-421

29. Cohen-Zion M, Ancoli-Israel S (2004) Sleep in children with attention-deficit hyperactivity disorder (ADHD): a review of naturalistic and stimulant intervention studies. Sleep Med Rev 8:379-402

30. Corrado D, Basso C, Thiene G (2001) Sudden cardiac death in young people with apparently normal heart. Cardiovasc Res 50:399-408

31. Cortese S, Faraone SV, Konofal E, Lecendreux M (2009) Sleep in children with attention-deficit/hyperactivity disorder: metaanalysis of subjective and objective studies. J Am Acad Child Adolesc Psychiatry 48:894-908

32. Denchev P, Kaltman JR, Schoenbaum M, Vitiello B (2010) Modeled economic evaluation of alternative strategies to reduce sudden cardiac death among children treated for attention deficit/hyperactivity disorder. Circulation 121:1329-1337

33. Dunn DW, Austin JK, Perkins SM (2009) Prevalence of psychopathology in childhood epilepsy: categorical and dimensional measures. Dev Med Child Neurol 51:364-372

34. Eli Lilly and Co. (2006) Strattera safety information

35. Elkins IJ, McGue M, Iacono WG (2007) Prospective effects of attention-deficit/hyperactivity disorder, conduct disorder, and sex on adolescent substance use and abuse. Arch Gen Psychiatry 64:1145-1152

36. Ernst M, Luckenbaugh DA, Moolchan ET, Leff MK, Allen R, Eshel N, London ED, Kimes A (2006) Behavioral predictors of substance-use initiation in adolescents with and without attention-deficit/hyperactivity disorder. Pediatrics 117:2030-2039
37. Faraone SV, Biederman J, Morley CP, Spencer TJ (2008) Effect of stimulants on height and weight: a review of the literature. J Am Acad Child Adolesc Psychiatry 47:994-1009

38. Faraone SV, Biederman J, Wilens TE, Adamson J (2007) A naturalistic study of the effects of pharmacotherapy on substance use disorders among ADHD adults. Psychol Med 37:1743-1752

39. Faraone SV, Giefer EE (2007) Long-term effects of methylphenidate transdermal delivery system treatment of ADHD on growth. J Am Acad Child Adolesc Psychiatry 46:1138-1147

40. Fayyad J, De Graaf R, Kessler R, Alonso J, Angermeyer M, Demyttenaere K, De Girolamo G, Haro JM, Karam EG, Lara C, Lepine JP, Ormel J, Posada-Villa J, Zaslavsky AM, Jin R (2007) Cross-national prevalence and correlates of adult attention-deficit hyperactivity disorder. Br J Psychiatry 190:402-409

41. Feijoo M, Bilbao J (1992) Seizures of sleep onset: clinical and therapeutical aspects. Clin Neuropharmacol 15:50-55

42. Feldman H, Crumrine P, Handen BL, Alvin R, Teodori J (1989) Methylphenidate in children with seizures and attention-deficit disorder. Am J Dis Child 143:1081-1086

43. Feldman PD, Ruff DD, Allen AJ (2005) Atomoxetine and tics in ADHD. J Am Acad Child Adolesc Psychiatry 44:405-406

44. Fritz KM, Butz C (2007) Attention deficit/hyperactivity disorder and pediatric burn injury: important considerations regarding premorbid risk. Curr Opin Pediatr 19:565-569

45. Gadde KM, Yonish GM, Wagner HR, Foust MS, Allison DB (2006) Atomoxetine for weight reduction in obese women: a preliminary randomised controlled trial. Int $\mathrm{J}$ Obes (Lond) 30(7):1138-1142

46. Gharib H, Cook DM, Saenger PH, Bengtsson BA, Feld S, Nippoldt TB, Rodbard HW, Seibel JA, Vance ML, Zimmerman D (2003) American Association of Clinical Endocrinologists medical guidelines for clinical practice for growth hormone use in adults and children-2003 update. Endocr Pract 9:64-76

47. Gonzalez-Heydrich J, Hsin O, Hickory M, Azeem MW, Mrakotsky C, Torres A, Mezzacappa E, DeMaso DR, Bourgeois B, Biederman J (2004) Comparisons of response to stimulant preparations in pediatric epilepsy. American Academy of Child and Adolescent Psychiatry Meeting

48. Gould MS, Walsh BT, Munfakh JL, Kleinmann M, Duan N, Olfson M, Greenhill L, Cooper T (2009) Sudden death and use of stimulant medications in youths. Am J Psychiatry 166:9921001

49. Graham J, Coghill D (2008) Adverse effects of pharmacotherapies for attention-deficit hyperactivity disorder: epidemiology, prevention and management. CNS Drugs 22:213-237

50. Greer CA, Alpern HP (1980) Paradoxical effects of D-amphetamine upon seizure susceptibility in 2 selectively bred lines of mice. Dev Psychobiol 13:7-15

51. Gross-Tsur V, Manor O, van der, Meere J, Joseph A, Shalev RS (1997) Epilepsy and attention deficit hyperactivity disorder: is methylphenidate safe and effective? J Pediatr 130:670-674

52. Gucuyener K, Erdemoglu AK, Senol S, Serdaroglu A, Soysal S, Kockar AI (2003) Use of methylphenidate for attention-deficit hyperactivity disorder in patients with epilepsy or electroencephalographic abnormalities. J Child Neurol 18:109-112

53. Halmoy A, Fasmer OB, Gillberg C, Haavik J (2009) Occupational outcome in adult ADHD: impact of symptom profile, comorbid psychiatric problems, and treatment: a cross-sectional study of 414 clinically diagnosed adult ADHD patients. J Atten Disord 13:175-187

54. Hanc T, Cieslik J (2008) Growth in stimulant-naive children with attention-deficit/hyperactivity disorder using cross-sectional and longitudinal approaches. Pediatrics 121:e967-e974 
55. Hechtman L, Weiss G, Perlman T (1984) Young adult outcome of hyperactive children who received long-term stimulant treatment. J Am Acad Child Psychiatry 23:261-269

56. Hemmer SA, Pasternak JF, Zecker SG, Trommer BL (2001) Stimulant therapy and seizure risk in children with ADHD. Pediatr Neurol 24:99-102

57. Hernandez A, Barragan P (2005) Efficacy of atomoxetine treatment in children with ADHD and epilepsy. Epilepsia 46(Suppl 6):718

58. Hesdorffer DC, Ludvigsson P, Olafsson E, Gudmundsson G, Kjartansson O, Hauser WA (2004) ADHD as a risk factor for incident unprovoked seizures and epilepsy in children. Arch Gen Psychiatry 61:731-736

59. Holtmann M, Becker K, Kentner-Figura B, Schmidt MH (2003) Increased frequency of rolandic spikes in ADHD children. Epilepsia 44:1241-1244

60. Hugtenburg JG, Griekspoor JE, De Boer I, Heerdink ER, Tso YH, Egberts AC (2005) Methylphenidate: use in daily practice. Pharm World Sci 27:197-201

61. Ismail D, O'Connell MA, Zacharin MR (2006) Dexamphetamine use for management of obesity and hypersomnolence following hypothalamic injury. J Pediatr Endocrinol Metab 19:129-134

62. Jackson LV, Thalange NK, Cole TJ (2007) Blood pressure centiles for Great Britain. Arch Dis Child 92:298-303

63. Jasinski DR, Faries DE, Moore RJ, Schuh LM, Allen AJ (2008) Abuse liability assessment of atomoxetine in a drug-abusing population. Drug Alcohol Depend 95:140-146

64. Jerome L (2001) Can methylphenidate facilitate sleep in children with attention deficit hyperactivity disorder? J Child Adolesc Psychopharmacol 11:109

65. Katusic SK, Barbaresi WJ, Colligan RC, Weaver AL, Leibson CL, Jacobsen SJ (2005) Psychostimulant treatment and risk for substance abuse among young adults with a history of attentiondeficit/hyperactivity disorder: a population-based, birth cohort study. J Child Adolesc Psychopharmacol 15:764-776

66. Keltikangas-Jarvinen L, Pulkki-Raback L, Puttonen S, Viikari J, Raitakari OT (2006) Childhood hyperactivity as a predictor of carotid artery intima media thickness over a period of 21 years: the cardiovascular risk in young Finns study. Psychosom Med 68:509-516

67. Kendall T, Taylor E, Perez A, Taylor C (2008) Diagnosis and management of attention-deficit/hyperactivity disorder in children, young people, and adults: summary of NICE guidance. BMJ 337:a1239

68. Kessler RC, Adler L, Barkley R, Biederman J, Conners CK, Demler O, Faraone SV, Greenhill LL, Howes MJ, Secnik K, Spencer T, Ustun TB, Walters EE, Zaslavsky AM (2006) The prevalence and correlates of adult ADHD in the United States: results from the National Comorbidity Survey Replication. Am J Psychiatry 163:716-723

69. King GA, Burnham WM (1980) Effects of D-amphetamine and apomorphine in a new animal model of petit mal epilepsy. Psychopharmacology (Berl) 69:281-285

70. Kinsbourne M (1973) Stimulants for insomnia. N Engl J Med 288:1129

71. Klein RG, Landa B, Mattes JA, Klein DF (1988) Methylphenidate and growth in hyperactive children. A controlled withdrawal study. Arch Gen Psychiatry 45:1127-1130

72. Kollins SH (2008) ADHD, substance use disorders, and psychostimulant treatment: current literature and treatment guidelines. J Atten Disord 12:115-125

73. Kollins SH, English J, Robinson R, Hallyburton M, Chrisman AK (2008) Reinforcing and subjective effects of methylphenidate in adults with and without attention deficit hyperactivity disorder (ADHD). Psychopharmacology (Berl)
74. Kratochvil C, Vaughan BS, Mayfield-Jorgensen ML, March J, Kollins S, Ravi H, Greenhill L, Kotler L, Paykina MA, Biggins BA, Stoner J (2006) A Pilot study of atomoxetine in young children with ADHD

75. Krzyzaniak A, Krzywinska-Wiewiorowska M, Stawinska-Witoszynska B, Kaczmarek M, Krzych L, Kowalska M, SzilagyiPagowska I, Palczewska I, Karch A, Josko J, Ostrowska-Nawarycz L, Nawarycz T (2009) Blood pressure references for Polish children and adolescents. Eur J Pediatr 168:1335-1342

76. Laurelle MD, Abi-Dargham A, van Dyck CH (1996) Single photon emission computerised tomography imaging of amphetamine-induced dopamine release in drug-free schizophrenic subjects. Proc Natl Acad Sci USA 93:9235-9240

77. Ledbetter M (2005) Atomoxetine use associated with onset of a motor tic. J Child Adolesc Psychopharmacol 15:331-333

78. Leddy JJ, Epstein LH, Jaroni JL, Roemmich JN, Paluch RA, Goldfield GS, Lerman C (2004) Influence of methylphenidate on eating in obese men. Obes Res 12:224-232

79. Lee TS, Lee TD, Lombroso PJ, King RA (2004) Atomoxetine and tics in ADHD. J Am Acad Child Adolesc Psychiatry 43:1068-1069

80. Leibson CL, Barbaresi WJ, Ransom J, Colligan RC, Kemner J, Weaver AL, Katusic SK (2006) Emergency department use and costs for youth with attention-deficit/hyperactivity disorder: associations with stimulant treatment. Ambul Pediatr 6:45-53

81. Lewington S, Clarke R, Qizilbash N, Peto R, Collins R (2002) Age-specific relevance of usual blood pressure to vascular mortality: a meta-analysis of individual data for one million adults in 61 prospective studies. Lancet 360:1903-1913

82. Livingston S, Pauli LL (1975) Dextroamphetamine for epilepsy. JAMA 233:278-279

83. Luo S, Michler K, Johnston P, Macfarlane PW (2004) A comparison of commonly used QT correction formulae: the effect of heart rate on the QTc of normal ECGs. J Electrocardiol 37(Suppl):81-90

84. Lurie S, O'Quinn A (1991) Neuroendocrine responses to methylphenidate and d-amphetamine: applications to attentiondeficit disorder. J Neuropsychiatry Clin Neurosci 3:41-50

85. Mannuzza S, Klein RG, Moulton JL III (2003) Does stimulant treatment place children at risk for adult substance abuse? A controlled, prospective follow-up study. J Child Adolesc Psychopharmacol 13:273-282

86. Mannuzza S, Klein RG, Truong NL, Moulton JL III, Roizen ER, Howell KH, Castellanos FX (2008) Age of methylphenidate treatment initiation in children with ADHD and later substance abuse: prospective follow-up into adulthood. Am J Psychiatry 165:604-609

87. Markowitz JS, Patrick KS (2001) Pharmacokinetic and pharmacodynamic drug interactions in the treatment of attentiondeficit hyperactivity disorder. Clin Pharmacokinet 40:753-772

88. Marras AR, Bassareo PP, Ruscazio M (2009) The prevalence of paediatric hypertension, emphasising the need to use specific population references: the Sardinian Hypertensive Adolescents Research Programme Study. Cardiol Young 19:233-238

89. Martins S, Tramontina S, Polanczyk G, Eizirik M, Swanson JM, Rohde LA (2004) Weekend holidays during methylphenidate use in ADHD children: a randomized clinical trial. J Child Adolesc Psychopharmacol 14:195-206

90. McAfee AT, Holdridge KC, Johannes CB, Hornbuckle K, Walker AM (2008) The effect of pharmacotherapy for attention deficit hyperactivity disorder on risk of seizures in pediatric patients as assessed in an insurance claims database. Curr Drug Saf 3:123-131

91. McCarthy S, Cranswick N, Potts L, Taylor E, Wong IC (2009) Mortality associated with attention-deficit hyperactivity disorder (ADHD) drug treatment: a retrospective cohort study of 
children, adolescents and young adults using the general practice research database. Drug Saf 32:1089-1096

92. Meltzer H, Harrington R, Goodman R, Jenkins R (1999) Children and adolescents who try to harm, hurt or kill themselves. A report of further analysis from the national survey of the mental health of children and adolescents in Great Britain in 1999. HMSO, London, pp 15-49

93. Michelson D, Read HA, Ruff DD, Witcher J, Zhang S, McCracken J (2007) CYP2D6 and clinical response to atomoxetine in children and adolescents with ADHD. J Am Acad Child Adolesc Psychiatry 46:242-251

94. Molina BS, Flory K, Hinshaw SP, Greiner AR, Arnold LE, Swanson JM, Hechtman L, Jensen PS, Vitiello B, Hoza B, Pelham WE, Elliott GR, Wells KC, Abikoff HB, Gibbons RD, Marcus S, Conners CK, Epstein JN, Greenhill LL, March JS, Newcorn JH, Severe JB, Wigal T (2007) Delinquent behavior and emerging substance use in the MTA at 36 months: prevalence, course, and treatment effects. J Am Acad Child Adolesc Psychiatry 46:1028-1040

95. Molina BS, Pelham WE (2001) Substance use, substance abuse, and LD among adolescents with a childhood history of ADHD. J Learn Disabil 34:333-342, 351

96. Mosholder AD, Gelperin K, Hammad TA, Phelan K, JohannLiang R (2009) Hallucinations and other psychotic symptoms associated with the use of attention-deficit/hyperactivity disorder drugs in children. Pediatrics 123:611-616

97. Muntner P, He J, Cutler JA, Wildman RP, Whelton PK (2004) Trends in blood pressure among children and adolescents. JAMA 291:2107-2113

98. Neuspiel DR, Kuller LH (1985) Sudden and unexpected natural death in childhood and adolescence. JAMA 254:1321-1325

99. Nissen SE (2006) ADHD drugs and cardiovascular risk. N Engl J Med 354:1445-1448

100. Noda T, Shimizu W, Satomi K, Suyama K, Kurita T, Aihara N, Kamakura S (2004) Classification and mechanism of Torsade de Pointes initiation in patients with congenital long QT syndrome. Eur Heart J 25:2149-2154

101. Odgers CL, Moffitt TE, Tach LM, Sampson A, Taylor RJ, Matthews CL, Caspi A (2009) The protective effects of neighborhood collective efficacy on British children growing up in deprivation: a developmental analysis. Dev Psychol 45:942-957

102. Ounsted C (1955) The hyperkinetic syndrome in epileptic children. Lancet 269:303-311

103. Paavonen EJ, Raikkonen K, Lahti J, Komsi N, Heinonen K, Pesonen AK, Jarvenpaa AL, Strandberg T, Kajantie E, PorkkaHeiskanen T (2009) Short sleep duration and behavioral symptoms of attention-deficit/hyperactivity disorder in healthy 7- to 8-year-old children. Pediatrics 123:e857-e864

104. Palumbo D, Spencer T, Lynch J, Co-Chien H, Faraone SV (2004) Emergence of tics in children with ADHD: impact of once-daily OROS methylphenidate therapy. J Child Adolesc Psychopharmacol 14:185-194

105. Parraga HC, Parraga KL, Harris DK, Campbell TS (2008) Abdominal tics during atomoxetine treatment in a child with ADHD: evaluation and differential diagnosis. CNS Spectr 13:E1

106. Parraga HC, Parraga MI, Harris DK (2007) Tic exacerbation and precipitation during atomoxetine treatment in two children with attention-deficit hyperactivity disorder. Int J Psychiatry Med 37:415-424

107. Pesonen AK, Raikkonen K, Paavonen EJ, Heinonen K, Komsi N, Lahti J, Kajantie E, Jarvenpaa AL, Strandberg T (2009) Sleep duration and regularity are associated with behavioral problems in 8-year-old children. Int $\mathrm{J}$ Behav Med

108. Pliszka SR, Matthews TL, Braslow KJ, Watson MA (2006) Comparative effects of methylphenidate and mixed salts amphetamine on height and weight in children with attention- deficit/hyperactivity disorder. J Am Acad Child Adolesc Psychiatry 45:520-526

109. Polanczyk G, de Lima MS, Horta BL, Biederman J, Rohde LA (2007) The worldwide prevalence of ADHD: a systematic review and metaregression analysis. Am J Psychiatry 164:942-948

110. Poncin Y, Sukhodolsky DG, McGuire J, Scahill L (2007) Drug and non-drug treatments of children with ADHD and tic disorders. Eur Child Adolesc Psychiatry 16(Suppl 1):78-88

111. Posner K, Oquendo MA, Gould M, Stanley B, Davies M (2007) Columbia Classification Algorithm of Suicide Assessment (CCASA): classification of suicidal events in the FDA's pediatric suicidal risk analysis of antidepressants. Am J Psychiatry 164:1035-1043

112. Poulton A (2005) Growth on stimulant medication; clarifying the confusion: a review. Arch Dis Child 90:801-806

113. Poulton A (2006) Growth and sexual maturation in children and adolescents with attention deficit hyperactivity disorder. Curr Opin Pediatr 18:427-434

114. Poulton A, Cowell CT (2003) Slowing of growth in height and weight on stimulants: a characteristic pattern. J Paediatr Child Health 39:180-185

115. Poulton R, Caspi A, Moffitt TE, Cannon M, Murray R, Harrington H (2000) Children's self-reported psychotic symptoms and adult schizophreniform disorder: a 15-year longitudinal study. Arch Gen Psychiatry 57:1053-1058

116. Robertson MM (2006) Attention deficit hyperactivity disorder, tics and Tourette's syndrome: the relationship and treatment implications. A commentary. Eur Child Adolesc Psychiatry 15:1-11

117. Roessner V, Becker A, Banaschewski T, Freeman RD, Rothenberger A (2007) Developmental psychopathology of children and adolescents with Tourette syndrome-impact of ADHD. Eur Child Adolesc Psychiatry 16(Suppl 1):24-35

118. Roessner V, Becker A, Banaschewski T, Rothenberger A (2007) Executive functions in children with chronic tic disorders with/ without ADHD: new insights. Eur Child Adolesc Psychiatry 16(Suppl 1):36-44

119. Roessner V, Robatzek M, Knapp G, Banaschewski T, Rothenberger A (2006) First-onset tics in patients with attention-deficithyperactivity disorder: impact of stimulants. Dev Med Child Neurol 48:616-621

120. Rothenberger A, Banaschewski T, Roessner V (2007) TicStörungen. Dritte Auflage, pp 319-325

121. Rothenberger A, Roessner V, Banaschewski T, Leckman JF (2007) Co-existence of tic disorders and attention-deficit/ hyperactivity disorder-recent advances in understanding and treatment. Eur Child Adolesc Psychiatry 16(Suppl 1):1-4

122. Sadeh A, Pergamin L, Bar-Haim Y (2006) Sleep in children with attention-deficit hyperactivity disorder: a meta-analysis of polysomnographic studies. Sleep Med Rev 10:381-398

123. Sangal RB, Owens J, Allen AJ, Sutton V, Schuh K, Kelsey D (2006) Effects of atomoxetine and methylphenidate on sleep in children with ADHD. Sleep 29:1573-1585

124. Scahill L, Erenberg G, Berlin CM Jr, Budman C, Coffey BJ, Jankovic J, Kiessling L, King RA, Kurlan R, Lang A, Mink J, Murphy T, Zinner S, Walkup J (2006) Contemporary assessment and pharmacotherapy of Tourette syndrome. NeuroRx 3:192-206

125. Schwartz G, Amor LB, Grizenko N, Lageix P, Baron C, Boivin $\mathrm{DB}$, Joober R (2004) Actigraphic monitoring during sleep of children with ADHD on methylphenidate and placebo. J Am Acad Child Adolesc Psychiatry 43:1276-1282

126. Sears J, Patel NC (2008) Development of tics in a thirteen-yearold male following atomoxetine use. CNS Spectr 13:301-303

127. Shillingford AJ, Glanzman MM, Ittenbach RF, Clancy RR, Gaynor JW, Wernovsky G (2008) Inattention, hyperactivity, and 
school performance in a population of school-age children with complex congenital heart disease. Pediatrics 121:e759-e767

128. Silka MJ, Hardy BG, Menashe VD, Morris CD (1998) A population-based prospective evaluation of risk of sudden cardiac death after operation for common congenital heart defects. J Am Coll Cardiol 32:245-251

129. Sonuga-Barke EJ, Oades RD, Psychogiou L, Chen W, Franke B, Buitelaar J, Banaschewski T, Ebstein RP, Gil M, Anney R, Miranda A, Roeyers H, Rothenberger A, Sergeant J, Steinhausen HC, Thompson M, Asherson P, Faraone SV (2009) Dopamine and serotonin transporter genotypes moderate sensitivity to maternal expressed emotion: the case of conduct and emotional problems in attention deficit/hyperactivity disorder. J Child Psychol Psychiatry 50:1052-1063

130. Sorof JM, Lai D, Turner J, Poffenbarger T, Portman RJ (2004) Overweight, ethnicity, and the prevalence of hypertension in school-aged children. Pediatrics 113:475-482

131. Spencer TJ, Biederman J, Harding M, O'Donnell D, Faraone SV, Wilens TE (1996) Growth deficits in ADHD children revisited: evidence for disorder-associated growth delays? J Am Acad Child Adolesc Psychiatry 35:1460-1469

132. Spencer TJ, Faraone SV, Biederman J, Lerner M, Cooper KM, Zimmerman B (2006) Does prolonged therapy with a longacting stimulant suppress growth in children with ADHD? J Am Acad Child Adolesc Psychiatry 45:527-537

133. Spencer TJ, Kratochvil CJ, Sangal RB, Saylor KE, Bailey CE, Dunn DW, Geller DA, Casat CD, Lipetz RS, Jain R, Newcorn JH, Ruff DD, Feldman PD, Furr AJ, Allen AJ (2007) Effects of atomoxetine on growth in children with attention-deficit/hyperactivity disorder following up to five years of treatment. J Child Adolesc Psychopharmacol 17:689-700

134. Spencer TJ, Newcorn JH, Kratochvil CJ, Ruff D, Michelson D, Biederman J (2005) Effects of atomoxetine on growth after 2year treatment among pediatric patients with attention-deficit/ hyperactivity disorder. Pediatrics 116:e74-e80

135. Spencer TJ, Sallee FR, Gilbert DL, Dunn DW, McCracken JT, Coffey BJ, Budman CL, Ricardi RK, Leonard HL, Allen AJ, Milton DR, Feldman PD, Kelsey DK, Geller DA, Linder SL, Lewis DW, Winner PK, Kurlan RM, Mintz M (2008) Atomoxetine treatment of ADHD in children with comorbid Tourette syndrome. J Atten Disord 11:470-481

136. Stein D, Pat-Horenczyk R, Blank S, Dagan Y, Barak Y, Gumpel TP (2002) Sleep disturbances in adolescents with symptoms of attention-deficit/hyperactivity disorder. J Learn Disabil 35:268-275

137. Stein MA, Blondis TA, Schnitzler ER, O'Brien T, Fishkin J, Blackwell B, Szumowski E, Roizen NJ (1996) Methylphenidate dosing: twice daily versus three times daily. Pediatrics 98:748756

138. Swanson J, Greenhill L, Wigal T, Kollins S, Stehli A, Davies M, Chuang S, Vitiello B, Skrobala A, Posner K, Abikoff H, Oatis M, McCracken J, McGough J, Riddle M, Ghuman J, Cunningham C, Wigal S (2006) Stimulant-related reductions of growth rates in the PATS. J Am Acad Child Adolesc Psychiatry 45:1304-1313

139. Swanson JM, Elliott GR, Greenhill LL, Wigal T, Arnold LE, Vitiello B, Hechtman L, Epstein JN, Pelham WE, Abikoff HB, Newcorn JH, Molina BS, Hinshaw SP, Wells KC, Hoza B, Jensen PS, Gibbons RD, Hur K, Stehli A, Davies M, March JS, Conners CK, Caron M, Volkow ND (2007) Effects of stimulant medication on growth rates across 3 years in the MTA followup. J Am Acad Child Adolesc Psychiatry 46:1015-1027

140. Taylor E, Dopfner M, Sergeant J, Asherson P, Banaschewski T, Buitelaar J, Coghill D, Danckaerts M, Rothenberger A, SonugaBarke E, Steinhausen HC, Zuddas A (2004) European clinical guidelines for hyperkinetic disorder-first upgrade. Eur Child Adolesc Psychiatry 13(Suppl 1):17-30
141. Thomas CR, Ayoub M, Rosenberg L, Robert RS, Meyer WJ (2004) Attention deficit hyperactivity disorder and pediatric burn injury: a preliminary retrospective study. Burns 30:221223

142. Tirosh E, Sadeh A, Munvez R, Lavie P (1993) Effects of methylphenidate on sleep in children with attention-deficient hyperactivity disorder. An activity monitor study. Am J Dis Child 147:1313-1315

143. Torres AR, Whitney J, Gonzalez-Heydrich J (2008) Attentiondeficit/hyperactivity disorder in pediatric patients with epilepsy: review of pharmacological treatment. Epilepsy Behav 12:217233

144. US Food and Drug Administration (2005) FDA alert: suicidal thinking in children

145. Upadhyaya HP, Rose K, Wang W, O'Rourke K, Sullivan B, Deas D, Brady KT (2005) Attention-deficit/hyperactivity disorder, medication treatment, and substance use patterns among adolescents and young adults. J Child Adolesc Psychopharmacol 15:799-809

146. Vetter VL, Elia J, Erckson C, Berger S, Blum N, Uzark K, Webb CL (2008) Cardiovascular monitoring of children and adolescents with heart disease receiving stimulant drugs: a scientific statement from the American Heart Association Council on Cardiovascular Disease in the Young. Circulation 117:24072423

147. Vetter VL, Elia J, Erickson C, Berger S, Blum N, Uzark K, Webb CL (2008) Cardiovascular monitoring of children and adolescents with heart disease receiving medications for attention deficit/hyperactivity disorder (corrected): a scientific statement from the American Heart Association Council on Cardiovascular Disease in the Young Congenital Cardiac Defects Committee and the Council on Cardiovascular Nursing. Circulation 117:2407-2423

148. Volkow ND, Swanson JM (2003) Variables that affect the clinical use and abuse of methylphenidate in the treatment of ADHD. Am J Psychiatry 160:1909-1918

149. Wernicke JF, Faries D, Breitung R, Girod D (2005) QT correction methods in children and adolescents. J Cardiovasc Electrophysiol 16:76-81

150. Wernicke JF, Faries D, Girod D, Brown J, Gao H, Kelsey D, Quintana H, Lipetz R, Michelson D, Heiligenstein J (2003) Cardiovascular effects of atomoxetine in children, adolescents, and adults. Drug Saf 26:729-740

151. Wernicke JF, Holdridge KC, Jin L, Edison T, Zhang S, Bangs ME, Allen AJ, Ball S, Dunn D (2007) Seizure risk in patients with attention-deficit-hyperactivity disorder treated with atomoxetine. Dev Med Child Neurol 49:498-502

152. Wilens TE, Adler LA, Adams J, Sgambati S, Rotrosen J, Sawtelle R, Utzinger L, Fusillo S (2008) Misuse and diversion of stimulants prescribed for ADHD: a systematic review of the literature. J Am Acad Child Adolesc Psychiatry 47:21-31

153. Wilens TE, Biederman J, Spencer T (1994) Clonidine for sleep disturbances associated with attention-deficit hyperactivity disorder. J Am Acad Child Adolesc Psychiatry 33:424-426

154. Wilens TE, Faraone SV, Biederman J (2004) Attention-deficit/ hyperactivity disorder in adults. JAMA 292:619-623

155. Wilens TE, Faraone SV, Biederman J, Gunawardene S (2003) Does stimulant therapy of attention-deficit/hyperactivity disorder beget later substance abuse? A meta-analytic review of the literature. Pediatrics 111:179-185

156. Wilens TE, Gignac M, Swezey A, Monuteaux MC, Biederman J (2006) Characteristics of adolescents and young adults with ADHD who divert or misuse their prescribed medications. J Am Acad Child Adolesc Psychiatry 45:408-414

157. Winterstein AG, Gerhard T, Shuster J, Johnson M, Zito JM, Saidi A (2007) Cardiac safety of central nervous system 
stimulants in children and adolescents with attention-deficit/ hyperactivity disorder. Pediatrics 120:e1494-e1501

158. Winterstein AG, Gerhard T, Shuster J, Saidi A (2009) Cardiac safety of methylphenidate versus amphetamine salts in the treatment of ADHD. Pediatrics 124:e75-e80

159. Wren C (2002) Sudden death in children and adolescents. Heart $88: 426-431$
160. Yap YG, Camm AJ (2003) Drug induced QT prolongation and torsades de pointes. Heart 89:1363-1372

161. Young $J$ (2008) Common comorbidities seen in adolescents with attention-deficit/hyperactivity disorder. Adolesc Med State Art Rev 19:216-228, vii 